\title{
Lamin B2 follows lamin A/C- mediated nuclear mechanics and cancer cell invasion efficacy
}

Short running title: Nuclear lamins in tumor cell migration

Marina Vortmeyer-Krause ${ }^{1} \dagger$, Mariska te Lindert ${ }^{1} \dagger$, Joost te $\operatorname{Riet}^{2} \dagger$, Veronika te Boekhorst ${ }^{1} \dagger$, Rene Marke ${ }^{1}$, Ramanil Perera ${ }^{1}$, Philipp Isermann ${ }^{3}$, Tom van Oorschot ${ }^{1}$, Monika Zwerger $^{3}$, Fengwei Yang ${ }^{4}$, Martin Svoreň ${ }^{1}$, Anotida Madzvamuse ${ }^{4}$, Jan Lammerding ${ }^{3}$, Peter Friedl ${ }^{1,5,6}$, Katarina Wolf ${ }^{1 *}$

†These authors contributed equally to this work.

* Correspondence to: katarina.wolf@radboudumc.nl

*Address of corresponding author: Department of Cell Biology (route 283), Radboud University Medical Center, PO Box 9101, 6500 HB Nijmegen, The Netherlands; katarina.wolf@radboudumc.nl; Orcid: http://orcid.org/0000-0003-0616-2708

\section{Affiliations}

${ }^{1}$ Radboud University Medical Center, Department of Cell Biology, 6500 HB Nijmegen, The Netherlands

${ }^{2}$ Radboud University Medical Center, Department of Tumor Immunology, 6500 HB Nijmegen, The Netherlands

${ }^{3}$ Weill Institute for Cell and Molecular Biology, Meinig School of Biomedical Engineering Cornell University, Ithaca, NY 14853; USA

${ }^{4}$ School of Mathematical and Physical Sciences, University of Sussex, Department of Mathematics, BN1 9QH, Falmer, Brighton, United Kingdom

${ }^{5}$ David H. Koch Center for Applied Research of Genitourinary Cancers, Department of Genitourinary Medical Oncology, The University of Texas MD Anderson Cancer Center, Houston, TX 77030, USA

${ }^{6}$ Cancer Genomics Center, 3584 CG Utrecht, The Netherlands 
Abbreviations: 2D, two-dimensional; 3D, three-dimensional; AFS, atomic force spectroscopy; ECM, extracellular matrix; H2B, histone-2B; MMP matrix metalloproteinase; NII, nuclear irregularity index; NT, non-targeting control; PDMS, polydimethylsiloxane

\section{Summary}

Nuclear deformability during cancer cell invasion and metastasis is critically regulated by lamin A. Here, researchers showed that lamin B2 also contributes to nuclear mechanics, implicating cooperating lamin networks regulating nuclear integrity, migration efficacy, and metastatic tumor progression.

Keywords: Nuclear lamins, Nuclear mechanics, Cell migration 


\begin{abstract}
Interstitial tumor cell invasion depends upon complex mechanochemical adaptation of both cell body and the rigid nucleus in response to extracellular tissue topologies. Nuclear mechanics during cell migration through confined environments is controlled by A-type lamins, however, the contribution of B-type lamins to the deformability of the nucleus remains unclear. Using systematic expression regulation of different lamin isoforms, we applied multi-parameter wet-lab and in silico analysis to test their impact on nuclear mechanics, shape regulation, and cancer cell migration. Modulation of lamin A/C and B2 but not B1 isoforms controlled nuclear deformation and viscoelasticity, whereby lamin B2 generally followed lamin A/C-mediated effects. Cell migration rates were altered by 5 to 9fold in dense collagen environments and synthetic devices, with accelerated rates after lamin downregulation and reverse effects after lamin upregulation, with migration rates strongly depending on nuclear shape change. These findings implicate cooperation of lamin B2 with lamin $\mathrm{A} / \mathrm{C}$ in regulating nuclear mechanics for shape adaptation and migration efficacy.
\end{abstract}




\section{Introduction}

Cell migration along or through complex three-dimensional (3D) tissues is an essential process during tissue formation, homeostasis and remodeling, however, also underlies tumor invasion and metastasis. Moving cells are confronted with connective tissue of varying topology and density, including loose fibrillar networks adjacent to densely packed, highly rigid stroma (Butcher et al., 2009; Charras and Sahai, 2014; Provenzano et al., 2008; Weigelin, 2012). Cells respond to these extracellular matrix (ECM) topologies and geometric confinements by either matrix metalloproteinase (MMP)-dependent proteolytic ECM degradation, or by reversibly deforming their shape (Wolf et al., 2003). To accommodate such shape changes, the ellipsoid nucleus, which is 2-10 times stiffer compared with the surrounding cytoplasm (Lammerding, 2011), undergoes complex deformation and transiently adapts elongated, hourglass-like or other, irregular shapes during cell passage through dense ECM. When the capacity of the nucleus to deform further is exhausted, it represents the ratelimiting organelle during cell migration (Davidson et al., 2014; Fu et al., 2012; Harada et al., 2014; Wolf et al., 2013).

The deformation kinetics of the cell nucleus in 3D environments is determined by its viscoelastic behavior, which can be modeled as a combination of springs and dashpots, and which collectively determine its deformability under mechanical forces. Elasticity (syn. stiffness, rigidity) describes how much the nucleus instantaneously deforms under force and reversibly bounces back into its original shape after force release, not unlike a rubber band.Viscosity describes the time-dependent behavior in response to force application, and often involves creep, i.e. continuous deformation under a constant load. The viscoelastic mechanical behavior of the nucleus depends on contributions from both the chromatin and the nuclear lamina, with chromatin primarily governing behavior for small deformations and the lamina dominating the mechanical resistance at larger extensions (Pajerowski et al., 2007; Stephens et al., 2017).

The nuclear lamina consists of a layer of interconnected intermediate filaments below the double nuclear membrane, forming a mechanosensitive cortical network, as well as nucleoplasmic filaments inside the nucleus (Kolb et al., 2011). The cortical filaments are formed by proteins of the lamin family, including A-type (A, C) and B-type (B1, B2) lamins which assemble into homotypic filaments and antiparallel polymers (Ho and Lammerding, 2012). While B-type lamins are expressed in all soft proliferating cells, A-type lamins become upregulated upon cell maturation and differentiation (Broers J.L.V., 2014; Constantinescu et al., 2006). Accordingly, A-type lamins were identified as primary mediators of nuclear 
stability and elasticity, using a range of experimental strategies including microaspiration, mechanical strain, microfluidic setups or atomic force spectroscopy (AFS) on adherent or suspended cells as well as on isolated nuclei (Davidson et al., 2014; Harada et al., 2014; Kaufmann et al., 2011; Lammerding et al., 2006; Lammerding et al., 2004; Lange et al., 2017; Lange et al., 2015; Lautscham et al., 2015; Schape et al., 2009; Swift et al., 2013). In addition, lamin A expression, often measured as lamin A:B ratio, positively correlated with ECM rigidity (Swift et al., 2013), indicating lamin A as the main structure mediating resistance to deformation force. Accordingly, migrating rates of nontransformed fibroblasts and invasive cancer cells in confining substrates in vitro, such as collagen, PDMS channels or transwell chambers, depend on the expression level of lamin A/C (Davidson et al., 2014; Greiner et al., 2014; Harada et al., 2014; Infante et al., 2018; Lautscham et al., 2015; Ribeiro et al., 2014; Rowat et al., 2013; Shin et al., 2013; Yadav et al., 2018), in line with findings that softer tumor cells associate with higher invasion rates (Swaminathan et al., 2011). With cancer progression, the de-differentiation of tumor cells and acquisition of stem cell properties is often accompanied by de-regulated A- as well as B-type lamin expression (Alhudiri et al., 2019; Broers J.L.V., 2014; Chow et al., 2012; Denais and Lammerding, 2014; Saarinen et al., 2015; Wazir et al., 2013). However, whereas the relevance of lamin A/C in regulating nuclear deformability and cell migration has been established, the role of B-type lamins is less clear. By combining biomechanical, functional and in silico analyses, we here address how both Aand B-type lamins control nuclear mechanics, and how their up- and downregulation translates to concordantly altered migration efficacy of invasive cancer cells. We identify lamin B2, in addition to the known functions of A-type lamins, as critical regulator of the viscoelasticity of the nucleus as well as of nuclear shape change and effective migration in intact cells. These data provide an inventory for complementary experimental techniques and models to dissect differential roles of lamin isoforms in nuclear mechanobiology and cell migration in environments of different dimensionality and complexity.

\section{Results}

Lamin expression regulation and distribution. Invasive HT1080 fibrosarcoma cells were used for probing lamin functions on nuclear mechanics and the capacity to migrate in 3D collagen (Krause et al., 2013; Wolf et al., 2013). HT1080 cells expressed lamin isoforms A/C, $\mathrm{B} 1$ and B2, which distributed around the chromatin in a rim-like fashion, and formed tubelike invaginations, here visible as intranuclear linear signal and speckles (Figs. 1A and B). HT1080 cell variants with down- or upregulated lamin A, C, B1 or B2 were generated and 
compensatory expression regulation by the other, non-targeted lamin isoforms was generally not detected (Figs. 1B and C; S1A). Transient downregulation for 48 hours by a pool of small inhibitory (si) RNAs (knockdown; RNAi) resulted in 11-40\% remaining protein levels in a lamin-dependent manner (Figs. 1B and D; S1B), and constitutive overexpression increased lamin protein levels by 2.3- to 4.5-fold (Figs. 1C and D). These changes of lamin isoform expression were confirmed on the single-cell level by immunofluorescence against specific lamin isoform, with weak but homogeneous residual lamin distribution at the nuclear rim after lamin downregulation (Figs. S1A and C). Conversely, lamin upregulation induced higher fluorescent signals at the nuclear lamina, as well as more prominent membrane foldings or intranuclear tubes, with the exception of lamin $\mathrm{C}$, which appeared to concentrate rather towards intranuclear tubes than the rim (Fig. S1D). Together, combining transient dowregulation and permanent upregulation in the same HT1080 cell source resulted in an 827 fold change from lowest to highest expression of the respective lamin isoforms (Fig. 1D).

Control of cell and nuclear mechanics by different lamin isoforms. To quantify and compare the impact of A- and B-type lamins on the deformability of a cell in response to transient compression, AFS combined with confocal microscopy was applied (Fig. 2A). We positioned the bead-functionalized cantilever on top of the nucleus of live HT1080 cells attached to plastic dishes during cell culture, and transiently compressed ('approached') the cell (Fig. 2B; Video1). To calculate the response of cell and nucleus to deformation relevant for cell migration in confinement (see Figs. 3A,B; 5) (Krause et al., 2013), we applied a broad force range between 1 and $1000 \mathrm{nN}$ on adherent cells. These yielded nuclear deformations from 0.5 to $\sim 4 \mu \mathrm{m}$ as a linear function, with a plateau reached at $200 \mathrm{nN}$ and $4 \mu \mathrm{m}$ indentation, from which small intendations were used for the calculation of the cells elastic modulus E (Fig. 2C). After lamin A/C down- or lamin A upregulation, elasticity values changed to 0.27 and $0.77 \mathrm{kPa}$ (as compared 0.41 and $0.47 \mathrm{kPa}$ in control cells; Fig. S2). Cell and nuclear stiffness thus was reduced to 0.66-fold or increased to 1.62-fold, respectively, when compared to normalized (1-fold) control values (Fig. 2D, Table 1). Similarly, the elastic modulus after lamin B2 downregulation was reduced 0.75-fold and after upregulation increased 1.43-fold, whereas no significant change was noted after deregulation of lamin B1 or C. Using $20 \mathrm{nN}$ compression force, indentation after depletion of lamin A/C increased from 2.9 to $3.25 \mu \mathrm{m}$ (thus by $12 \%$ ), and to 3.1 after lamin B2 downregulation (thus by $7 \%$ ), but remained again unchanged after lamin B1 pertubation (Fig. 2E). Similar softening was noted when forces up to $150 \mathrm{nN}$ were used (Fig. 2F). Thus, deep (3-4 $\mu \mathrm{m})$ and more subtle $(0.5 \mu \mathrm{m})$ 
indentation yielded comparable results for a function of lamins $\mathrm{A} / \mathrm{C}$ and $\mathrm{B} 2$ in nuclear deformability. In line with these data, regulation of nuclear deformation by lamin A/C using microfluidics, aspiration, nuclear strain or AFS experimentation previously yielded 1.5 to 4fold changes (Davidson et al., 2014; Harada et al., 2014; Kaufmann et al., 2011; Lammerding et al., 2006; Lange et al., 2015), whereas the impact of lamin B2 deregulation on nuclear stiffness was not investigated.

As an independent assay, and to exclude potential confounding effects from apical actin fibers that span the nucleus in adherent cells and may thus affect the AFS measurements, we measured nuclear deformability of HT1080 cells in suspension using a microfluidic micropipette aspiration assay (Fig. 2G; Video 2). Cells depleted for lamin A/C and for lamin B2 showed similar, significantly increased nuclear deformation compared to non-target controls and lamin B1 depleted cells at short times indicative of nuclear stiffness (Fig. 2D, left). Over longer times, indicating viscous properties, nuclear deformation increased more in cells with downregulated lamin A/C than lamin B2 levels, with both cell types exhibiting significantly larger nuclear deformations than the NT and lamin B1 depleted cells. As consequence, after 120 seconds control cell nuclei became aspirated into the pipet to a length of $7.4 \mu \mathrm{m}$, yet aspiration was increased by 1.18 -fold after lamin B2 knockdown and by 1.35fold after lamin A/C downregulation (Fig. 2H, right).

To validate the relevance of lamin B2 in the control of nuclear mechanics, lamin expression was modulated in a number of additional cell types (Fig. S3A,D,G). AFS measurements confirmed, when compared to respective control values, a reduced stiffness after lamin B2 downregulation (0.66-fold) in MV3 melanoma cells whereas overexpression, vice versa, resulted in 1.30-fold increased elasticity in MDA-MB-231 breast cancer cells, respectively (Fig. S3B, E). Likewise, nuclear strain experiments in MCF10A breast cancer cells after lamin B2 overexpression showed a 1.5 fold reduced capacity of the cells to stretch,. In all measurements, these values were again exceeded by 0.62 -fold after lamin $\mathrm{A}$ downregulation (Fig. S3B), and 1.35- and 4-fold after lamin A upregulation, respectively (Fig. S3E, H). In summary, downregulation of lamin A/C and lamin B2 increased, whereas lamin $\mathrm{A} / \mathrm{C}$ and $\mathrm{B} 2$ overexpression reduced, the capacity of the nucleus to deform. In contrast, effects on lamin B1 in mediating stiffness to the cell nucleus were either not present (HT1080 cells; MDA-MB231 cells) or contrasted each other (MV3 and MCF-10A cells; Figs. 2D; S3B,E,H; Table 1). We therefore did not further follow up on a mechanical role of lamin B1 in mediating cell migration in confinement. Instead, we here conclude that lamin B2 follows 
lamin $\mathrm{A} / \mathrm{C}$ in contributing to the viscoelastic behavior of the nucleus and determining its mechanical deformability.

\section{Lamin isoform-induced alterations in cell migration rates through dense collagen}

lattices. To assess whether the change in nuclear deformability associated with variation in lamin A/C and B2 levels affects migration efficacy in complex environments, HT1080 cells were tested in 3D fibrillar collagen lattices of different pore size ranges, based on previous quantitative pore calibration (Denais et al., 2016; Wolf et al., 2013). These included ECM lattices which either enable migration when nuclei deform ('confining'; pore cross-section 5$25 \mu^{2}$ ) or support fast migration without significant physical impact on nuclear shape ('nonconfining'; pores 50-150 $\mu^{2}$; generated by low collagen polymerization temperature or migration of cells in the presence of MMP-dependent collagen degradation; Figs. 3A, S4A). Accordingly, HT1080 cells moving through fibrillar collagen of confining density developed irregular shapes with local deformations (Fig. 3B), and with a speed of around $0.25 \mu \mathrm{m} / \mathrm{min}$ were below the speed range achieved in non-confining conditions (Fig. S4B-E; Video 3). After lamin A/C downregulation, migration speed in confinement increased to 1.65-1.8 fold, followed by a 1.2-1.55 fold increase after lamin B2 knockdown (Figs. 3C; S4B; Video 4). Notably, lamin isotype downregulation by $100 \mathrm{nM}$ RNAi had a 10-30\% stronger impact on migration, compared to $10 \mathrm{nM}$ siRNA. Conversely, lamin overexpression caused a 4-5 fold speed delay after overexpression of lamins A, followed by B2 and lamin C (Figs. 3C; S4D; Video 5). Similarly, MDA-MB-231 cells in confining collagen conditions after downregulation of lamin A/C migrated 1.4-fold faster than non-targeted control cells (10 nM RNAi; data not shown), and upregulation of lamin A decreased migration speed to $30 \%$ as compared to control cell rates, followed by lamin B2 and C upregulation (Figs. 3C; S3F, left; Video 7). Notably, fast migration speed after lamin depletion was accompanied by decreased elastic modulus, and vice versa, for all lamin isoforms, though at somewhat different strength (Figs. 3C,D). Thus, by contributing to nuclear viscoelasticity, all lamin A/C and B2 mediate 5-9 fold different migration rates through confined spaces in fibrillar collagen.

Next, we examined whether changes in lamin levels affect cell migration speed in general, or only in confined conditions when the nucleus has to deform. In non-confining 3D collagen conditions migration depends on adhesion and cytoskeletal contractility-mediated mechanocoupling, but not on deformation of the nucleus (Fig. 3A) (Wolf et al., 2013). Here, similar cell migration rates in MDA-MB-231 and HT1080 cells were obtained, irrespective of lamin expression levels (Figs. S3F, right; Video 7; S4C,E). Likewise, when cells migrated 
across glass surfaces, median migration rates were not or only moderately decreased after upor downregulation of lamin isoforms (Fig. S4F). These data indicate that lamin B2, like lamin $\mathrm{A} / \mathrm{C}$ mediated migration speed in confining tissue space is controlled predominantly by nuclear mechanics rather than nucleo-cytoskeletal bonds.

\section{Altered cell migration rates through synthetic substrates of defined pore size after lamin}

deregulation. To confirm data in a spatially precise and complementary porous environment, we tested migration across transwell membranes with pores of uniform size and shape (either 5 or $8 \mu \mathrm{m}$ diameter; Fig. 4A). Similar as to 3D collagen, transmigration of HT1080 cells through filter pores providing spatial confinement was increased after lamin downregulation and decreased after upregulation, with a similar contribution by each tested lamin isotype (Figs. 4B; S5A and B, each left). Transmigration data generated for MV3 melanoma cells showed a similar, 2-fold increase after lamin A downregulation, followed by lamin B2 (Figs. 4B; S3C). Generally, no changes were noted at non-confining pores (Figs. S3C, right; S5A and $\mathrm{B}$, right), confirming that the basic migration ability of both cell types was unperturbed. As second engineered model, we used custom-developed microfluidic, polydimethylsiloxane (PDMS) migration devices that were functionalized with collagen and that provide precise confinement [Fig. 4C (Davidson et al., 2015)]. In addition, in contrast to polycarbonate transwell filters, these 3-dimensional environments are ideally suited for live cell imaging. The median transmigration rate of HT1080 cells through confining $10 \mu \mathrm{m}^{2}$ constrictions was 15 minutes. Downregulation of lamins A/C accelerated the transit 1.7-fold, followed by lamin B2, whereas transit time through unconfined pores remained unaffected (Figs. 4D; S5C; Video 6). Together, the impact of the different lamin isoforms on migration efficacy in confinement is similar in both collagen models and synthetic substrates.

To test whether a less rigid nucleus will allow migration at conditions that usually restrict migration due to limited nuclear deformation, cells were allowed to migrate within increased confinement (3-9 $\mu \mathrm{m}^{2}$ effective pore sizes; Fig. S5D). At these pore sizes, (trans)migration efficacy, as compared to confining conditions, further declined to $0.18 \mu \mathrm{m} / \mathrm{min}$ (collagen), $50 \%$ transmigration rate (transwell chamber) or 1.7-fold increased, 25 minute-long pore transit time (microchannel), indicating increasing mechanically impeding confinement (Fig. S5E-G). In most models, downregulation of lamin A/C significantly, and lamin B2 knockdown mildly, enhanced migration rates in HT1080 cells (Figs. 4E; S5E-G). Likewise, a 120 minute-long pore passage time by MDA-MB-231 control cells in a microdevice was accelerated after lamin A/C downregulation followed by lamin B2 in $5 \mu \mathrm{m}^{2}$, but not in $75 \mu \mathrm{m}^{2}$ 
pores (Fig. S5H). This nuclear deformation in strong confinement was accompanied by nuclear envelope (NE) rupture in $68 \%$ of all HT1080 cells, and was thus 40 -fold increased when compared to non-confinement (Fig. S5I). NE ruptures further increased in small pores with depletion of each tested lamin isoform, in accordance with previously acquired MDAMB-231 cell data (Denais et al., 2016). In summary, lamin B2 follows lamin A/C in regulating migration efficacy in confining and near-limiting $3 \mathrm{D}$, but not in unconfining $3 \mathrm{D}$ or 2D environments.

Lamin expression-dependent nuclear deformation during migration. The data so far indicated that lamin B2, like lmin A/C, modulates cell speed primarily through regulating the viscoelasticity of the nucleus, and thereby facilitates or impede migration in mechanically demanding 3D environments. We therefore tested whether lamin regulation directly affects the maximal deformation of nuclei during 3D migration. As a control, downregulation of lamin isoforms yielded near-equal nuclear diameters between around $10-11 \mu \mathrm{m}$.in yet round HT1080 cells suspended into a 3D network in the moment of collagen polymerization (Fig. 5A). After 15-20 hours of migration, when control cells developed nuclear diameters of $7 \mu \mathrm{m}$, lamin downregulation supported 120-140\% increased deformations (Fig. 5B,C). The percentage of nuclei where the smallest nuclear diameter was $\leq 3 \mu \mathrm{m}$, corresponding to the 'physical migration limit' (Wolf et al., 2013), increased from 3\% in control cells to 8-15\% in cells where lamins were downregulated, with notable shape pleomorphism ranging from elliptic to multi-indented shapes (Fig. 5B). To address whether lamin expression regulation exceeds the limit of nuclear deformation during migration, only the diameters of deformed nuclei were measured. Lamin downregulation decreased the smallest nuclear diameters of 4.2 $\mu \mathrm{m}$ in control cells down to $3 \mu \mathrm{m}$, and reciprocally increased the number of nuclei with extreme deformation from $7 \%$ in control cells to $23 \%$ for lamin B2 and to $50 \%$ for lamin A/C (Fig. 5D). Vice versa, lamin upregulation in HT1080 cells led to 1.2 to 1.5 -fold enlarged cytoplasmic protrusions in confining collagen (Fig. 6A, upper row; B; Video 5), as well as to rounded nuclei reminiscent of migration-abrogated cells (Figs. 6A, bottom row; S5D) (Wolf et al., 2013). Nuclear diameters of $6.5 \mu \mathrm{m}$ from control cells increased by $26 \%$ after lamin B2, and more dominantly (by 45\%) after lamin A overexpression in HT1080 cells (Fig. 6C). Similarly, an increase of nuclear diameters from around 4 to $6 \mu \mathrm{m}(150 \%)$ in MDA-MB-231 cells occured in dense, but not in loose, matrix (Figs. 6D,E). Accordingly, not more than $2 \%$ cells per population reached nuclear diameters of $\leq 3 \mu \mathrm{m}$ (Fig. 6C,E), in contrast to numbers after lamin downregulation. Together, these data indicate that excess expression of lamins A 
or B2 decreases the capacity of the nucleus to deform, thereby exhausting migration at pore sizes that are usually confining. Thus, nuclear diameters during migration are controlled by lamin isoforms $\mathrm{A} / \mathrm{C}$ and $\mathrm{B} 2$, concordant to the cells nuclear mechanics and inverse to migration speed (Fig. 6F,G).

Increased dynamic nuclear shape change after lamin downregulation. Lastly, to examine whether lamin-mediated nuclear deformation underlies nuclear shape dynamics, we analyzed the morphological changes that cell nuclei undergo during constricted migration. Sequences from in-focus nuclei during cell migration were collected and nuclear morphologies extracted (Fig. 7A, Video 8). Subsequent nuclear shapes were rotated for a maximal overlap to take directional changes during migration into account and remaining changes between irregular shapes over time were calculated as nuclear shape fluctuation (Fig. 7B) (Krause et al., 2019). These shape changes increased most after downregulation of lamin A/C and were again followed by lamin B2 downregulation (Fig. 7C; see Video 8). Thus, these lamins are important regulators of shape maintenance in a graded fashion, where depletion of each lamin isoform increases nuclear deformability and shape adaptation for increased migration rates in confinement with heterogeneously formed pores (Fig. 7D). In summary, by regulating nuclear mechanics, $\mathrm{A} / \mathrm{C}$ and $\mathrm{B} 2$ alone or together control nuclear deformation for migration rates and nuclear integrity.

\section{Discussion}

By probing migrating tumor cells with low or high lamin isoform expression levels in 3D substrate of optimal, confining or near-limiting porosity relative to cell size, we have identified roles for each lamin isoform in nuclear mechanics and migration. Besides A-type lamins (Davidson et al., 2014; Harada et al., 2014), we show that the lamin isoform B2, but not B1, regulates nuclear material properties, including elasticity, viscoelasticity and deformation in a non-redundant manner. Perturbation of lamins A/C and B2 caused changes in nuclear deformation during constricted migration. These ranged from complex shape adaptations prone to nuclear envelope rupture after lamin downregulation to a poorly deformable, roundish nucleus after lamin overexpression. Consequently, the reduction of each lamin isoform increased cell migration, whereas upregulation caused strong migration delay (Wolf et al., 2013), thus regulating speed by up to 9-fold (Fig. 8). Our data may imply the existence of a cooperating lamin network, with all lamin isoforms fulfilling non-redundant as 
well as overlapping functions in regulating nuclear shape adaptation and integrity during migration in $3 \mathrm{D}$ environments.

\section{Regulation of nuclear mechanics and cell migration by B-type lamins}

According to their early presence of in soft proliferating stem cells and lack of regulation by surrounding tissue stiffness (Swift et al., 2013), B-type lamins have been accounted a role in nuclear organization, rather than contributing to nuclear mechanics. This view was supported by the lack of lamin B1-mediated effects in nuclear deformation measurements under strain, using Lmnb1 $^{\Delta / \Delta}$ mouse embryonic fibroblasts (Lammerding et al., 2006). Others reported that nuclear stiffness as measured by AFS increased with lamin B1 expression in skin fibroblasts after $L M N B 1$ gene duplication in autosomal dominant leukodystrophy patients, as well as after ectopic lamin B1 expression in HEK293 and neuronal N2a cells (Ferrera et al., 2014). On the contrary, lamin B1 depletion stiffened the nucleus as shown by micropipette aspiration (Shin et al., 2013), especially when lamin A/C levels were low (Stephens et al., 2017), as well as increased nucleolar stiffness as shown by AFS (Louvet et al., 2014). These contradicting results were consistent with our own results. Thus, overall, the impact of lamin B1 on the maintenance of cell stiffness may be cell type-dependent, but may also depend on the levels of other lamin isoforms.

Because of the overall not apparent or contrary effects mediated by especially lamin B1, a contribution of lamin B2 to nuclear mechanics was overlooked so far. Here, by combining AFS and micropipette aspiration to mechanically deform the nucleus to similar extents as nuclear deformations required for 3D migration, we found a robust contribution of lamin $\mathrm{B} 2$ to nuclear mechanics. Following lamin A/C in magnitude, the contribution of lamin B2 to nuclear deformability was revealed in four independent cell models and by three different techniques, and therefore likely can be generalized.

\section{Cooperating lamin networks}

The impact of lamin B2 levels on nuclear deformability and migration implies non-redundant and overlapping functions with A-type lamins in stabilizing nuclear mechanics. Indeed, originally thought to form separate layers (Goldberg et al., 2008a; Goldberg et al., 2008b), Aand B-type lamins form strongly interlinked networks of particular porosity ('face areas') to regulate stability of the nucleus in MEF cells (Shimi et al., 2015; Turgay et al., 2017). Accordingly, knockout of the LMNA gene mildly increased the porosity of the B-type lamin network (Shimi et al., 2015). This effect might be supported by a biochemical study 
demonstrating that the stability of the lamin B2 network requires interaction with the other, i.e. A-type lamin polymer network (Schirmer and Gerace, 2004). Together, this may show that the structural meshwork properties of individual lamins depend on the presence of the respective other lamin isotypes.

\section{Implications for cell navigation in complex environments}

To rule out a major effect on the general migration machinery after lamin depletion (Corne et al., 2016; Hale et al., 2008), we tested migration across ECM-coated glass and large pore 3D conditions and detected no principal migration defect when cells move in non-confining conditions. When, however, comparing speed changes under confinement, downregulation of lamins allow acceleration by 1.5 -fold in 3D collagen and PDMS channels and up to 2.5-fold crossing transwell membranes. Conversely, upregulation of all lamin isoforms resulted in around $20-25 \%$ remaining migration rates in both $3 \mathrm{D}$ collagen or transwell membranes. This indicates that adaptation of nuclear deformation is the primary mechanism to facilitate or impede cell migration in 3D confinement. Thus, irrespective of cell type, ligand density, 3D substrate stiffness, or the (ir)regularity of pore shapes, lamin expression levels control nuclear deformability and migration rates. By regulating the ability of cells to move into and through dense tissue, with a total amplitude of $870 \%$ from fastest to slowest condition, lamin expression thus represents a central regulator of cell mechanics for cell navigation through 3D tissue. Cells with high lamin levels and limited deformability may retain full ability to navigate through ECM environments of wide space, including linear tracks present in the connective tissue and between myofibers in the living organism. In addition, cells with stiffer nuclei may retain a stronger ability to deform and compress the tissue during migration, which may support proteolytic remodeling and tissue disruption (Wolf et al., 2007). Conversily, cells with low lamin expression may additionally be able to disseminate through dense and complex-shaped ECM, including irregular clefts between adipocytes or traverse across dense basement membranes (Glentis et al., 2017; Weigelin, 2012). Thus, rather than providing a stop signal for migration, nuclear deformability may dictate routes of preference based on available space and alignment of tissue structures.

\section{Implications for cancer progression}

Besides regulating cell migration, A-and B-type lamins may cooperate in protecting the cell nucleus against mechanical assault caused by deformation and extracellular shear stress. When being deformed towards high nuclear curvature by moving individually through dense 
ECM, cancer cells and leukocytes with low lamin A/C, B1 or B2 expression all experience nuclear envelope ruptures, followed by DNA damage and, potentially, genomic instability, nuclear fragmentation and cell survival (Denais et al., 2016 ; Harada et al., 2014; Hatch et al., 2013; Hatch, 2016; Irianto et al., 2017; Raab et al., 2016; Xia et al., 2018). Thus, downregulation of A- and B-type lamins may impose a dual effect on cancer progression, by facilitating dissemination into a vast range of tissue spaces, as well as supporting invasionassociated DNA damage and, potentially, cancer aggressiveness. Conversely, lamin upregulation may mechanically protect the nucleus by limiting deformation and steering migration into more defined tissue routes. Because intratumor heterogeneity with both up- and downregulated lamin expression is a typical feature of neoplasia (Chow et al., 2012; de Las Heras et al., 2013), it remains to be investigated whether and how invasion patterns and nuclear integrity status including DNA damage and cell survival are affected by lamin deregulation during cancer disease.

\section{Acknowledgements}

We thank Celine Denais and Kathy Zhang for help with the microfluidic migration device assays; Jos Broers for providing the GFP-laminA vector; Esther Wagena and Stephanie Alexander for the generation of stable cell lines and western blotting; Lisette Meerstein and Louis Wolf for help with image processing and analysis; Ineke van der Zee for help with statistical analysis; Ben Fabry for helpful discussions on AFS analysis; the RIMLS Microscopic Imaging Center for the use of facilities, in particular the combined AFS-confocal microscope (NWO Medium Sized Investment Grant 91110007); as well as the Cornell NanoScale Facility (CNF) where microdevices were fabricated (NNCI member supported by NSF Grant NNCI-1542081).

This project was supported by the Netherlands Science Organization (NWO-VENI 680.47.421 to JtR; NWO-VIDI 917.10.364 to K.W.; NWO-VICI 918.11.626 to P.F.) and the Dutch Cancer Foundation KWF (grant number 11199 to K.W); by the Leverhulme Trust Research Project Grant (RPG-2014-149 to FWY and AM) and the European Union's Horizon 2020 research innovation program (Marie Sklodowska-Curie grant 642866 to AM); and by National Institutes of Health awards (R01 HL082792 and U54 CA210184 to JL); a Department of Defense Breast Cancer Breakthrough Award (BC150580 to JL) and a National Science Foundation CAREER award (CBET-1254846 to JL). 


\section{Competing interests}

The authors declare no competing financial interests.

\section{Separate author contribution}

K.W. and P.F. conceived and designed the experiments and were supported by J.L. and J.tR. M.VK., M.KtL., J.tR., V.tB., R.M., R.P., P.I., T.vO., M.Z. and K.W. performed the experiments.

M.VK., M.KtL., J.tR., V.tB., R.M., R.P., P.I., T.vO., F.Y., M.S. and K.W. analysed the data. J.L. and M.Z. contributed material, and J.tR., A.M. and F.Y. contributed analysis tools.

K.W., P.F. and M.VK. wrote the paper.

All authors read and corrected the manuscript.

\section{Materials and Methods}

\section{Antibodies and dyes}

The following antibodies, isotypic IgGs and fluorescent dyes were used: monoclonal mouse anti-lamin A/C IgG1 (clone 131C3; Acris), polyclonal goat anti-lamin A/C (sc6215; Santa Cruz Biotechnology), polyclonal goat anti-lamin B1 (sc6217-M20; Santa Cruz

Biotechnology), monoclonal mouse anti-lamin B2 IgG (clone X223; Progen), polyclonal rabbit anti-lamin B2 (10895-1-AP; ProteinTechGroup); monoclonal mouse anti- $\beta$-tubulin IgG1 (clone E7; Developmental Studies Hybridoma Bank, University of Iowa); monoclonal rabbit anti-GAPDH IgG (clone 14C10; Cell Signaling Technology) and polyclonal anti- $\beta$ actin (Abcam) were used for confocal microscopy or western blotting. Secondary goat antimouse IgG and rabbit anti-goat IgG conjugated to horseradish peroxide (ECL; Thermo Fisher Scientific), or a fluorophore specific to the Odyssee system (IRDye 680RD and IRDye 800RD; LI-COR Biosciences) were used for western blotting, and secondary Alexa Fluor 488-conjugated pre-absorbed goat anti-mouse, donkey anti-goat and goat anti-rabbit IgGs (Invitrogen), Alexa Fluor 488 or 647-conjugated phalloidin (Invitrogen), and DAPI (Sigma) were used for confocal microscopy.

\section{Cell lines and lamin expression modulation approaches}

The following cell lines were used: human HT1080 fibrosarcoma cells (ACC315, DSMZ Braunschweig, Germany), MV3 melanoma cells (Maaser et al., 1999), MDA-MB-231 breast cancer cells (Moss et al., 2009) and MCF10A breast epithelial cells. HT1080, MV3 and MDA-MB-231 cells were cultured at $37^{\circ} \mathrm{C}$ and $5 \% \mathrm{CO}_{2}$ humidified atmosphere in Dulbecco's modified Eagle medium (DMEM; Invitrogen), supplemented with $10 \%$ fetal calf serum (FCS; 
Sigma Aldrich), $2 \mathrm{mM}$ L-glutamine, $1 \mathrm{mM}$ sodium pyruvate (Invitrogen) and $100 \mathrm{U} / \mathrm{ml}$ penicillin and $100 \mu \mathrm{g} / \mathrm{ml}$ streptomycin (PAA). MCF10A cells were cultured in DMEM/HAM12 medium supplemented with $5 \%$ horse serum, $0.5 \mu \mathrm{g} / \mathrm{ml}$ hydrocortisone, 5 $\mu \mathrm{g} / \mathrm{ml}$ insulin, and 10ng/ml EGF. Cell lines were used untreated; or modified for either lamin expression as described below, or for stable expression of fluorescent markers such as nuclear histone-2B (H2B)-coupled GFP, H2B-mCherry, NLS-GFP, or GFP-lamin A, alone or in combination (Denais et al., 2016). Briefly, for the generation of HT1080 cells stably expressing GFP-Lamin A, lamin A DNA in a pEGF-C1 vector (provided by J. Broers, Maastricht University) was transfected into wild type HT1080 cells by Lipofectamin 2000, selected with neomycin for stable expression, sorted twice, and clonally selected for moderate GFP- lamin A expression [clone 1, (Denais et al., 2016)]. Further, after transduction with lentiviral nuclear H2B-coupled GFP or H2B-mCherry constructs, HT1080 cells were selected by blasticidine and FACS sorted for high expression. To modulate lamin expression, cells were either treated with specific siRNAs for transient lamin knockdown or stably transduced with vectors encoding lamin genes.

For transient lamin knockdown, cells were cultured in antibiotics-free supplemented DMEM in 6-well plates (each 250.000 cells) for $24 \mathrm{~h}$. Cells were treated with a pool of small interfering (si) RNAs consisting of 4 single RNAs each and targeting expression of lamin $\mathrm{A} / \mathrm{C}$, lamin B1, or lamin B2 protein, or non-targeting (NT) negative control (on-target plus, SMARTpool; Dharmacon). The forward 21-nucleotide siRNA sequences for the NT control were 5-UGGUUUACAUGUCGACUAA-3, 5-UGGUUUACAUGUUGUGUGA-3, 5UGGUUUACAUGUUUUCUGA-3, 5-UGGUUUACAUGUUUUCCUA-3; for siLMNA the forward sequences were 5-GAAGGAGGGUGACCUGAUA-3, 5-

UCACAGCACGCACGCACUA-3, 5-UGAAAGCGCGCAAUACCAA-3, 5-

CGUGUGCGCUCGCUGGAAA-3; for siLMNB1, the forward sequences were 5AAUAGAAGCUGUGCAAUUA-3, 5-GAUCAAGCUUCGAGAAUAU-3, 5GCAUGAAACGCGCUUGGUA-3, 5-GCGCAAGCCCUUCAUGAGA-3 and for siLMNB2 the forwards sequences were 5-UAACGCGGAUGGCGAGGAA-3, 5GAGAUCGCCUACAAGUUCA-3, 5-GUGAAGAAGUCCUGGUGA-3, 5CCUCGACGCUGGUGUGGAA-3. siRNAs were transferred into cells with Dharmafect 4 transfection reagent according to the manufacturer's protocol and cultured with antibioticsfree DMEM for $48 \mathrm{~h}$ prior to characterization and functional studies. Viability of cells after exposure to Dharmafect reagent and specific RNAi's was confirmed by the lack of membrane damage detected by staining with propidium iodide (Sigma) and flow cytometry, which 
resulted in 91-97\% propidium iodide-negative cells at each condition, indicating membrane integrity; and intact migration function (see Figs. S4B, C for lamin-specific siRNA during migration compared to untreated control cells, or within collagen providing optimized pore conditions).

For stable lamin overexpression in HT1080 wildtype cells, human lamin $L M N A, L M N C$, LMNB1 or LMNB2 DNAs [UniProt P02545-1 (prelamin A); P02545-2 (lamin C); P20700 (lamin B1); and Q03252 (lamin B2 short version according to (Schumacher et al., 2006)] were cloned into lentiviral PCDH-EF1-MCS1-puro vectors (System Biosciences). Lentiviruses were produced by cotransfection of lentiviral target plasmids (ENV, Pol, GAG) with the respective lamin containing or empty (Mock) vectors into HEK 293-TN cells using PureFection nanotechnology-based transfection reagent (System Biosciences). The medium was exchanged the next day and replaced by antibiotics-free DMEM containing 10\% FCS. Lentivirus-containing supernatants were collected at $48 \mathrm{~h}$ and $72 \mathrm{~h}$ after transfection, filtered through a $0.45 \mu \mathrm{m}$ filter and used as viral stock that HT1080 cells were transduced with for at least 3 consecutive days, in the presence of $8 \mu \mathrm{g} / \mathrm{mL}$ freshly prepared polybrene (SigmaAldrich). The viral solution was removed and cells were incubated in fresh medium for further $24 \mathrm{~h}$ before then being sub-cultured under continuous puromycin selection. For the production of retrovirally transduced MDA-MB-231 cells, retroviral target plasmids (ENV, Pol, GAG) were co-transfected with the respective lamin-transfected pRetroX-IRES-ZsGreen vectors into HEK 293 cells and the procedure proceeded as for the lentivirally transduced HT1080 cells. Retrovirally transduced MDA-MB-231 cell lines were tested by reverse transcriptase (PERT) assay (University of Zürich, Switzerland), and the absence of retrovirus production and secretion into the cell culture supernatant was confirmed. Because of the absence of a neomycin resistance gene in retrovirally transduced MDA-MB-231 lines, cells were FACS-sorted and the stability of lamin expression confirmed by flow cytometry for over 10-15 passages, during which experiments were performed.

\section{SDS-Page and Western Blotting}

Lamin knockdown and overexpression efficiencies were determined by electrophoresis and western blot analysis from whole-cell lysates (62.5 mM Tris-HCl; 2\% w/v SDS; $10 \%$ glycerol; $50 \mathrm{mM}$ DTT; $0.01 \% \mathrm{w} / \mathrm{v}$ bromophenol blue), followed by either chemiluminescence detection (ECL detection kit; GE Healthcare) or fluorescence detection (Odyssee; LI-COR Biosciences) and densitometric analysis (Fiji ImageJ). 


\section{Nuclear deformability measurements by AFS}

Imaging and quantification of cell deformation, elastic modulus and dissipation were performed on a Catalyst BioScope atomic force microscope (Bruker, Santa Barbara, CA) combined with a 3-channel confocal microscope TCS SP5 II (Leica; 20×/NA 0.70 or $40 \times /$ NA 0.85 air objectives). The measurements on nuclear deformation and elastic properties, including the conversion of force-deformation into force-indentation $(\mathrm{F}-\delta)$ curves were performed as described (Krause et al., 2013). Briefly, 1 or 2 days before experiments, 40,000 or 80,000 cells were seeded in a Willco dish supplemented with DMEM/10 \% FCS. Cells were probed by defined forces and at a speed of $10 \mu \mathrm{m} / \mathrm{sec}$ using calibrated cantilevers coupled to $10 \mu \mathrm{m}$-diameter beads (NP-S, type D, nominal spring constant of $0.06 \mathrm{~N} / \mathrm{m}$, Bruker, for the calculation of the elastic modulus; or NSG11, type B, nominal spring constant of $5.5 \mathrm{~N} / \mathrm{m}$, NT-MDT, for the generation of the approach-retraction sequence; see Fig. S2A). After the measurements and after baseline correction, $\mathrm{F}-\delta$ curves were fitted over a 0 - up to $1000 \mathrm{nN}$ range. To calculate the elastic modulus, an in-house written Igor Pro 6 (WaveMetrics) algorithm was applied using the simplified Hertz model for spheres in contact with a flat surface and deformations less than $10 \%$ of the original height, thus without the requirement to correct for sample affinity and non-linearity (Krause et al., 2013; Lin et al., 2009).

For the visualization of cell deformation by AFS probing optically assisted AFS measurements were performed with a speed of $250 \mathrm{~nm} / \mathrm{s}$ and using fluorescent Crimsonlabeled $10 \mu$ m-diameter beads (Invitrogen), as previously published (Krause et al., 2013).

\section{Micropipette aspiration assay}

PDMS microfluidic devices were fabricated and used as previously described (Denais et al., 2016). In brief, the device was passivated with $2 \%$ BSA and $0.2 \%$ FCS blocking solution to prevent cell adhesion to the PDMS and cells were subsequently perfused into the device. The device was pressurized at 1-2 psi on the cell side to deform the nuclei into the constrictions. Dimensions of the micropipette channels were $5 \mu \mathrm{m}$ in height and $3 \mu \mathrm{m}$ in width. Imaging was performed at $37^{\circ} \mathrm{C}$ on an inverted Zeiss Observer $\mathrm{Z} 1$ microscope equipped with a CCD camera (Photometrics CoolSNAP KINO) using a 20×/NA 0.8 air objective, and image acquisition was automated through ZEN (Zeiss) software with imaging intervals of $2 \mathrm{sec}$ collecting images for DIC and GFP. Nuclear transit times were determined by a customwritten automated image analysis program as described previously (Elacqua et al., 2018). 


\section{Nuclear strain experiments}

Substrate strain experiments to measure nuclear stiffness were performed as described previously (Lombardi et al., 2011; Zwerger et al., 2013). In brief, cells were plated on fibronectin-coated silicone membranes, incubated with Hoechst 33342 to DNA, and subjected to $\sim 20 \%$ uniaxial strain using a custom-build microscope-mounted strain device. Nuclear strain was calculated based on fluorescence images of the cell nucleus before, during, and after strain application and normalized to the applied membrane strain. Cells that became damaged or detached during the stain application were excluded from the subsequent analysis.

\section{Preparation of 3D collagen lattices}

Acidic rat-tail collagen type I solution [Becton Dickinson, BD, for all experiments unless indicated otherwise; or from S. Weiss lab (Wolf et al., 2013), for Fig. S4A only]; or acidic bovine collagen type I solution (Nutragon, Advanced BioMatrix; for all experiments with MDA-MB-231 cells) were used to generate fibrillar collagen matrices (1.7 or $2.5 \mathrm{mg} / \mathrm{mL})$ for 3D migration experiments. Lattices were reconstituted in vitro by raising the $\mathrm{pH}$ to $7.4 \mathrm{using}$ either $\mathrm{NaOH}$ and buffering by $25 \mu \mathrm{M}$ Hepes (Sigma-Aldrich) for rat tail collagen, or $0.75 \%$ Na-bicarbonate solution (Gibco) for bovine dermal collagen, together with minimum essential Eagle's medium (Sigma-Aldrich), and were polymerized at $37^{\circ} \mathrm{C}$ unless indicated otherwise. Collagen lattices were used either cell-free or with cells $(20.000 / 100 \mu l)$, which were suspended in neutralized collagen solution before polymerization and placed as droplet into a well insert or self-constructed chamber (Wolf et al., 2013). After polymerization, supplemented medium was added and, where indicated, broad spectrum matrix metalloproteinase (MMP) inhibitor GM6001 (Ilomastat; $20 \mu \mathrm{M}$, unless stated otherwise; Calbiochem) was added to both collagen-cell suspensions and supernatants.

\section{Time-lapse-microscopy and quantitative cell tracking}

Cells seeded at low density on glass bottom Willco dishes or cell-collagen cultures were monitored by temperature- and $\mathrm{CO}_{2}$-controlled bright-field inverse microscopy $\left(37^{\circ} \mathrm{C}, 5 \%\right.$; air objectives, 10×, NA 0.20, Leica; 20×, NA 0.30, Leica; and 10×, NA 0.25, Nikon DiaPhot 300). Images were collected by CCD cameras (Sentech or Hamamatsu C8484-05G), and either the 16-channel frame grabber software (Vistek) or the 2D time lapse software version 2.7 (Okolab) was used at 4-minute frame intervals for up to $30 \mathrm{~h}$ (Wolf et al., 2013). Migration speed was quantified by computer-assisted cell tracking [Autozell 1.0 software; Center for Computing and Communication Technologies (TZI), University of Bremen, 
Germany] for the generation of XY paths with 4-12 min step intervals. The average speed per cell was calculated from the length of the path divided by time, including "go" and "stop" phases. Only viable cells that showed dynamic changes in cytoplasmic extensions and retractions including mitosis were tracked and included into the analysis.

\section{Boyden chamber transmigration assay}

Transwell migration experiments were performed as described previously in (Wolf et al., 2013). Briefly, $6.5 \mathrm{~mm}$ diameter transwell chambers with uncoated polycarbonate filters of 8 , 5 , and $3 \mu \mathrm{m}$ diameters pore size (BD and Costar) were filled with 30.000 cells suspended in DMEM supplemented with $2 \%$ FCS. Cells migrated through the porous membrane into the lower transwell chamber containing supplemented DMEM/ 10\% FCS and pro-migratory agent lysophosphatidic acid (LPA; $10 \mu \mathrm{M}$; Sigma) for $20 \mathrm{~h}$. The remaining cells on the upper membrane side were removed by a cotton swab, and the transmigrated cells attached to the lower membrane side were fixed, stained with crystal violet, embedded by mowiol, imaged and counted.

\section{Microfluidic migration devices}

PDMS microfluidic devices were fabricated and used as previously described (Davidson et al., 2014; Denais et al., 2016), with a migration chamber height of $5 \mu \mathrm{m}$ and a pore width of either 1,2 or $15 \mu \mathrm{m}$, resulting in 5,10 and $75 \mu \mathrm{m}^{2}$ cross-sectional areas. In brief, the migration devices were coated with rat tail type-I collagen $(50 \mu \mathrm{g} / \mathrm{mL}$; BD Biosciences $)$ in acetic acid $(0.02 \mathrm{~N})$ or human plasma fibronectin $(5 \mu \mathrm{g} / \mathrm{mL}$; Millipore) in PBS overnight at $4^{\circ} \mathrm{C}$ and rinsed with imaging medium to remove the coating solution. After loading the cells, devices were incubated for at least 3 hours to allow cell attachment before imaging. Microfluidic migration devices were imaged at $37^{\circ} \mathrm{C}$ on an inverted Zeiss Observer Z1 microscope equipped with a CCD camera (Photometrics CoolSNAP KINO) using a 20×/NA 0.8 air objective. The image acquisition was automated through ZEN (Zeiss) software with imaging intervals of 5 min collecting images for DIC and GFP. Time-series images were stabilized using a custom written MATLAB (Mathworks) script that used features of the PDMS device as fiducials to compensate for the inaccuracy of the linear encoded microscope stage. Individual cells were tracked during the process of pore transmigration by using a custom written Matlab script (Elacqua et al., 2018) with manual verification.

\section{Confocal fluorescence and reflection microscopy and image analysis}


For fixed-cell microscopy, cells were cultured on glass for $24 \mathrm{~h}$, or in polymerized collagen for $0-20 \mathrm{~h}$ before fixation with $2 \%$ or $4 \%$ buffered PFA or methanol, permeabilized with $0.1 \%$ Triton100, and stained with the indicated primary and secondary antibodies and dyes. Samples were monitored by confocal laser scanning microscopy (Zeiss LSM 510, 40×/NA 1.3 oil objective and 40x/NA 0.8 water objective; Olympus, 20x/NA 0.5 water objective and 40x/NA 0.8 water objective) with simultaneous 3-5 channel scanning for fluorescence, reflection and transmission signal, and as z-stacks of 1-2 $\mu \mathrm{m}$ distance. For life-cell microscopy, cells were monitored by a BD Pathway 855 high content microscope with spinning disk (20×/NA 0.75 air objective), or a Leica SP5 laser scanning microscope using a temperature- and $\mathrm{CO}_{2}$-controlled stage $\left(37^{\circ} \mathrm{C}, 5 \%\right)$.

Image analysis was performed by Fiji ImageJ (software version 1.40v; National Institutes of Health): XY image stacks were either displayed as single scan, reconstructed as maximal projections, or reconstructed as $\mathrm{XZ}$ images using the reslice function, as indicated in legends. In still images, elongation index (length/width) and the smallest nuclear diameter of cells were calculated from images after indicated hours of migration within collagen. Round nonmoving, apoptotic or mitotic cells, as identified morphologically by actin signal, or from the movie sequence and transmission signals, were excluded from analysis. Image processing was performed by cropping, rotation, and manual adjustment of contrast and brightness and displayed in virtual colors.

Dynamic changes in nuclear shapes over time were analyzed as in (Krause et al., 2019). In brief, image stacks were thresholded, nuclear outlines generated, and nuclear fluctuation [as adapted from (Lee et al., 2014)] calculated. Fluctuation was calculated by overlaying the two consecutive images with their centroids and performing a $1^{\circ}$-stepwise full-circle $\left(360^{\circ}\right)$ rotation for the maximum overlap between these two shapes. The resulting fluctuation number was computed through

$$
\text { Fluctuation }=\frac{A_{1}+A_{2}-2\left(A_{1} \cap A_{2}\right)}{A_{1}+A_{2}},
$$

where $A_{1}, A_{2}$ are the areas of the two consecutive nuclear shapes (monitored 4 min after eachother) and $A_{1} \cap A_{2}$ are the maximum intersections found through the rotation.

\section{Statistics}

Significance was determined by the two-tailed unpaired Students t-test (western blots, transmigration rates, NLS leakage), or a two-tailed unpaired Mann-Whitney test for nongaussian distributed cell samples (image analyses, AFS measurements, migration rates), 
respectively, using the GraphPad Prism 5 program. In order to compare data from individual experiments (n's), one median from all the respective control cell measurements was calculated, and a correction factor applied on the data of the individual experiment (see detailed explanation in legend of Fig. S2).

\section{Online supplemental material}

Fig. S1 shows lamin levels in populations of HT1080 cells after modulation of lamin isoforms.

Fig. S2 describes the principles and measurements from lamin-modulated HT1080 cells derived by atomic force microscopy.

Fig. S3 shows data generated from additional cell lines MV3 melanoma, MDA-MB-231 and MCF10A breast cancer cells after down- and upregulation of lamin isoforms.

Fig. S4 depicts collagen pore size ranges from different collagen sources, and HT1080 cell migration data in collagen after lamin modulation.

Fig. S5 shows data on HT1080 and MDA-MB cell migration after lamin modulation in transwell chamber and microchannel assays, as well as NE rupture incidence.

Video 1 shows compression and decompression of the nucleus from a GFP-lamin A expressing HT1080 cell by a bead coupled cantilever.

Video 2 shows aspiration of HT1080 cells and their colored nucleus into a micropipette by the application of high pressure.

Video 3 shows a confocal microscopy-derived time sequence of a single HT1080 cell migrating in confining collagen and adapting its nucleus labeled with $\mathrm{H} 2 \mathrm{~B}$-mCherry and GFP-lamin A.

Video 4 shows the effect of lamin isoform downregulation on HT1080 cell migration rates in confining collagen.

Video 5 shows the effect of lamin isoform overexpresssion on HT1080 cell migration rates and cell morphology in confining collagen.

Video 6 shows nuclear pore passage time of HT1080 cells after lamin isoform downregulation in a snythetic microdevice.

Video 7 shows the effect of lamin A overexpresssion on MDA-MB-231 cell migration rates and cell morphology in confining and optimal collagen pore conditions.

Video 8 shows the nuclear rotation method for analysis of nuclear fluctuation. 
Video 9 shows segmented nuclear shapes and their dynamic changes in HT1080 cells migrating in confining collagen after downregulation of lamin isoforms.

Figure legends, Supplementary figure legends, Video legends: see Figure part

\section{References}

Alhudiri, I.M., C.C. Nolan, I.O. Ellis, A. Elzagheid, E.A. Rakha, A.R. Green, and C.J. Chapman. 2019. Expression of Lamin A/C in early-stage breast cancer and its prognostic value. Breast Cancer Res Treat.

Broers J.L.V., R.F.C.S. 2014. The Role of the Nuclear Lamina in Cancer and Apoptosis. E.C. Schirmer and J.I. de las Heras (eds.), Cancer Biology and the Nuclear Envelope, Advances in Experimental Medicine and Biology. (C) Springer Science+Business Media New York 2014. 773.

Butcher, D.T., T. Alliston, and V.M. Weaver. 2009. A tense situation: forcing tumour progression. Nat Rev Cancer. 9:108-122.

Charras, G., and E. Sahai. 2014. Physical influences of the extracellular environment on cell migration. Nat Rev Mol Cell Biol. 15:813-824.

Chow, K.H., R.E. Factor, and K.S. Ullman. 2012. The nuclear envelope environment and its cancer connections. Nature reviews. Cancer. 12:196-209.

Constantinescu, D., H.L. Gray, P.J. Sammak, G.P. Schatten, and A.B. Csoka. 2006. Lamin A/C expression is a marker of mouse and human embryonic stem cell differentiation. Stem Cells. 24:177-185.

Corne, T.D., T. Sieprath, J. Vandenbussche, D. Mohammed, M. Te Lindert, K. Gevaert, S. Gabriele, K. Wolf, and W.H. De Vos. 2016. Deregulation of focal adhesion formation and cytoskeletal tension due to loss of A-type lamins. Cell Adh Migr:1-17.

Davidson, P.M., C. Denais, M.C. Bakshi, and J. Lammerding. 2014. Nuclear deformability constitutes a rate-limiting step during cell migration in 3-D environments. Cell Mol Bioeng. 7:293-306.

Davidson, P.M., J. Sliz, P. Isermann, C. Denais, and J. Lammerding. 2015. Design of a microfluidic device to quantify dynamic intra-nuclear deformation during cell migration through confining environments. Integr Biol (Camb). 7:1534-1546.

de Las Heras, J.I., D.G. Batrakou, and E.C. Schirmer. 2013. Cancer biology and the nuclear envelope: a convoluted relationship. Seminars in cancer biology. 23:125-137.

Denais, C., and J. Lammerding. 2014. Nuclear mechanics in cancer. Adv Exp Med Biol. 773:435-470.

Denais, C.M., R.M. Gilbert, P. Isermann, A.L. McGregor, M. te Lindert, B. Weigelin, P.M. Davidson, P. Friedl, K. Wolf, and J. Lammerding. 2016. Nuclear envelope rupture and repair during cancer cell migration. Science. 352:353-358.

Elacqua, J.J., A.L. McGregor, and J. Lammerding. 2018. Automated analysis of cell migration and nuclear envelope rupture in confined environments. PLoS One. 13:e0195664.

Ferrera, D., C. Canale, R. Marotta, N. Mazzaro, M. Gritti, M. Mazzanti, S. Capellari, P. Cortelli, and L. Gasparini. 2014. Lamin B1 overexpression increases nuclear rigidity in autosomal dominant leukodystrophy fibroblasts. FASEB J. 28:3906-3918.

Fu, Y., L.K. Chin, T. Bourouina, A.Q. Liu, and A.M. VanDongen. 2012. Nuclear deformation during breast cancer cell transmigration. Lab Chip. 12:3774-3778.

Glentis, A., P. Oertle, P. Mariani, A. Chikina, F. El Marjou, Y. Attieh, F. Zaccarini, M. Lae, D. Loew, F. Dingli, P. Sirven, M. Schoumacher, B.G. Gurchenkov, M. Plodinec, and D.M. Vignjevic. 2017. Cancer-associated fibroblasts induce metalloprotease-independent cancer cell invasion of the basement membrane. Nat Commun. 8:924. 
Goldberg, M.W., J. Fiserova, I. Huttenlauch, and R. Stick. 2008a. A new model for nuclear lamina organization. Biochem Soc Trans. 36:1339-1343.

Goldberg, M.W., I. Huttenlauch, C.J. Hutchison, and R. Stick. 2008b. Filaments made from A- and Btype lamins differ in structure and organization. J Cell Sci. 121:215-225.

Greiner, A.M., M. Jackel, A.C. Scheiwe, D.R. Stamow, T.J. Autenrieth, J. Lahann, C.M. Franz, and M. Bastmeyer. 2014. Multifunctional polymer scaffolds with adjustable pore size and chemoattractant gradients for studying cell matrix invasion. Biomaterials. 35:611-619.

Hale, C.M., A.L. Shrestha, S.B. Khatau, P.J. Stewart-Hutchinson, L. Hernandez, C.L. Stewart, D. Hodzic, and D. Wirtz. 2008. Dysfunctional connections between the nucleus and the actin and microtubule networks in laminopathic models. Biophysical journal. 95:5462-5475.

Harada, T., J. Swift, J. Irianto, J.W. Shin, K.R. Spinler, A. Athirasala, R. Diegmiller, P.C. Dingal, I.L. Ivanovska, and D.E. Discher. 2014. Nuclear lamin stiffness is a barrier to 3D migration, but softness can limit survival. The Journal of cell biology. 204:669-682.

Hatch, E.M., A.H. Fischer, T.J. Deerinck, and M.W. Hetzer. 2013. Catastrophic nuclear envelope collapse in cancer cell micronuclei. Cell. 154:47-60.

Hatch, E.M.H., M.W. 2016. Nuclear envelope rupture is induced by actin-based nucleus confinement Journal of Cell Biology. x:x.

Ho, C.Y., and J. Lammerding. 2012. Lamins at a glance. J Cell Sci. 125:2087-2093.

Infante, E., A. Castagnino, R. Ferrari, P. Monteiro, S. Aguera-Gonzalez, P. Paul-Gilloteaux, M.J. Domingues, P. Maiuri, M. Raab, C.M. Shanahan, A. Baffet, M. Piel, E.R. Gomes, and P. Chavrier. 2018. LINC complex-Lis1 interplay controls MT1-MMP matrix digest-on-demand response for confined tumor cell migration. Nat Commun. 9:2443.

Irianto, J., Y. Xia, C.R. Pfeifer, A. Athirasala, J. Ji, C. Alvey, M. Tewari, R.R. Bennett, S.M. Harding, A.J. Liu, R.A. Greenberg, and D.E. Discher. 2017. DNA Damage Follows Repair Factor Depletion and Portends Genome Variation in Cancer Cells after Pore Migration. Curr Biol. 27:210-223.

Kaufmann, A., F. Heinemann, M. Radmacher, and R. Stick. 2011. Amphibian oocyte nuclei expressing lamin A with the progeria mutation E145K exhibit an increased elastic modulus. Nucleus. 2:310-319.

Kolb, T., K. Maass, M. Hergt, U. Aebi, and H. Herrmann. 2011. Lamin A and lamin C form homodimers and coexist in higher complex forms both in the nucleoplasmic fraction and in the lamina of cultured human cells. Nucleus. 2:425-433.

Krause et al., F.W.Y., Mariska te Lindert, Philipp Isermann, Jan Schepens, Ralph Maas, Khouloud Eid, Chandrasekhar Venkataraman, Jan Lammerding, Anotida Madzvamuse, Wiljan Hendriks, Joost te Riet, Katarina Wolf 2019. Cell migration in 3D confinement: speed accelerations by deformation and recoil of the

nucleus Phil Trans $R$ Soc B:x-x.

Krause, M., J. Te Riet, and K. Wolf. 2013. Probing the compressibility of tumor cell nuclei by combined atomic force-confocal microscopy. Phys Biol. 10:065002.

Lammerding, J. 2011. Mechanics of the nucleus. Compr Physiol. 1:783-807.

Lammerding, J., L.G. Fong, J.Y. Ji, K. Reue, C.L. Stewart, S.G. Young, and R.T. Lee. 2006. Lamins A and C but not lamin B1 regulate nuclear mechanics. J Biol Chem. 281:25768-25780.

Lammerding, J., P.C. Schulze, T. Takahashi, S. Kozlov, T. Sullivan, R.D. Kamm, C.L. Stewart, and R.T. Lee. 2004. Lamin A/C deficiency causes defective nuclear mechanics and mechanotransduction. The Journal of clinical investigation. 113:370-378.

Lange, J.R., C. Metzner, S. Richter, W. Schneider, M. Spermann, T. Kolb, G. Whyte, and B. Fabry. 2017. Unbiased High-Precision Cell Mechanical Measurements with Microconstrictions. Biophys J. 112:1472-1480.

Lange, J.R., J. Steinwachs, T. Kolb, L.A. Lautscham, I. Harder, G. Whyte, and B. Fabry. 2015. Microconstriction arrays for high-throughput quantitative measurements of cell mechanical properties. Biophys J. 109:26-34.

Lautscham, L.A., C. Kammerer, J.R. Lange, T. Kolb, C. Mark, A. Schilling, P.L. Strissel, R. Strick, C. Gluth, A.C. Rowat, C. Metzner, and B. Fabry. 2015. Migration in Confined 3D Environments Is 
Determined by a Combination of Adhesiveness, Nuclear Volume, Contractility, and Cell Stiffness. Biophys J. 109:900-913.

Lee, C.P., M. Wirtz, and R. Hell. 2014. Evidence for Several Cysteine Transport Mechanisms in the Mitochondrial Membranes of Arabidopsis thaliana. Plant Cell Physiol. 55:64-73.

Lin, D.C., D.I. Shreiber, E.K. Dimitriadis, and F. Horkay. 2009. Spherical indentation of soft matter beyond the Hertzian regime: numerical and experimental validation of hyperelastic models. Biomechanics and modeling in mechanobiology. 8:345-358.

Lombardi, M.L., M. Zwerger, and J. Lammerding. 2011. Biophysical assays to probe the mechanical properties of the interphase cell nucleus: substrate strain application and microneedle manipulation. J Vis Exp.

Louvet, E., A. Yoshida, M. Kumeta, and K. Takeyasu. 2014. Probing the stiffness of isolated nucleoli by atomic force microscopy. Histochem Cell Biol. 141:365-381.

Maaser, K., K. Wolf, C.E. Klein, B. Niggemann, K.S. Zanker, E.B. Brocker, and P. Friedl. 1999. Functional hierarchy of simultaneously expressed adhesion receptors: integrin alpha2beta1 but not CD44 mediates MV3 melanoma cell migration and matrix reorganization within threedimensional hyaluronan-containing collagen matrices. Mol Biol Cell. 10:3067-3079.

Moss, N.M., Y.I. Wu, Y. Liu, H.G. Munshi, and M.S. Stack. 2009. Modulation of the membrane type 1 matrix metalloproteinase cytoplasmic tail enhances tumor cell invasion and proliferation in three-dimensional collagen matrices. J Biol Chem. 284:19791-19799.

Pajerowski, J.D., K.N. Dahl, F.L. Zhong, P.J. Sammak, and D.E. Discher. 2007. Physical plasticity of the nucleus in stem cell differentiation. Proc Natl Acad Sci U S A. 104:15619-15624.

Provenzano, P.P., D.R. Inman, K.W. Eliceiri, J.G. Knittel, L. Yan, C.T. Rueden, J.G. White, and P.J. Keely. 2008. Collagen density promotes mammary tumor initiation and progression. BMC Med. 6:11.

Raab, M., M. Gentili, H. de Belly, H.R. Thiam, P. Vargas, A.J. Jimenez, F. Lautenschlaeger, R. Voituriez, A.M. Lennon-Dumenil, N. Manel, and M. Piel. 2016. ESCRT III repairs nuclear envelope ruptures during cell migration to limit DNA damage and cell death. Science. 352:359-362.

Ribeiro, A.J., P. Khanna, A. Sukumar, C. Dong, and K.N. Dahl. 2014. Nuclear stiffening inhibits migration of invasive melanoma cells. Cell Mol Bioeng. 7:544-551.

Rowat, A.C., D.E. Jaalouk, M. Zwerger, W.L. Ung, I.A. Eydelnant, D.E. Olins, A.L. Olins, H. Herrmann, D.A. Weitz, and J. Lammerding. 2013. Nuclear envelope composition determines the ability of neutrophil-type cells to passage through micron-scale constrictions. J Biol Chem. 288:8610-8618.

Saarinen, I., T. Mirtti, H. Seikkula, P.J. Bostrom, and P. Taimen. 2015. Differential Predictive Roles of A- and B-Type Nuclear Lamins in Prostate Cancer Progression. PLoS One. 10:e0140671.

Schape, J., S. Prausse, M. Radmacher, and R. Stick. 2009. Influence of lamin A on the mechanical properties of amphibian oocyte nuclei measured by atomic force microscopy. Biophysical journal. 96:4319-4325.

Schirmer, E.C., and L. Gerace. 2004. The stability of the nuclear lamina polymer changes with the composition of lamin subtypes according to their individual binding strengths. J Biol Chem. 279:42811-42817.

Schumacher, J., M. Reichenzeller, T. Kempf, M. Schnolzer, and H. Herrmann. 2006. Identification of a novel, highly variable amino-terminal amino acid sequence element in the nuclear intermediate filament protein lamin B(2) from higher vertebrates. FEBS Lett. 580:6211-6216.

Shimi, T., M. Kittisopikul, J. Tran, A.E. Goldman, S.A. Adam, Y. Zheng, K. Jaqaman, and R.D. Goldman. 2015. Structural organization of nuclear lamins A, C, B1, and B2 revealed by superresolution microscopy. Mol Biol Cell. 26:4075-4086.

Shin, J.W., K.R. Spinler, J. Swift, J.A. Chasis, N. Mohandas, and D.E. Discher. 2013. Lamins regulate cell trafficking and lineage maturation of adult human hematopoietic cells. Proceedings of the National Academy of Sciences of the United States of America. 110:18892-18897. 
Stephens, A.D., E.J. Banigan, S.A. Adam, R.D. Goldman, and J.F. Marko. 2017. Chromatin and lamin A determine two different mechanical response regimes of the cell nucleus. Mol Biol Cell. 28:1984-1996.

Swaminathan, V., K. Mythreye, E.T. O'Brien, A. Berchuck, G.C. Blobe, and R. Superfine. 2011. Mechanical stiffness grades metastatic potential in patient tumor cells and in cancer cell lines. Cancer research. 71:5075-5080.

Swift, J., I.L. Ivanovska, A. Buxboim, T. Harada, P.C. Dingal, J. Pinter, J.D. Pajerowski, K.R. Spinler, J.W. Shin, M. Tewari, F. Rehfeldt, D.W. Speicher, and D.E. Discher. 2013. Nuclear lamin-A scales with tissue stiffness and enhances matrix-directed differentiation. Science. 341:1240104.

Turgay, Y., M. Eibauer, A.E. Goldman, T. Shimi, M. Khayat, K. Ben-Harush, A. Dubrovsky-Gaupp, K.T. Sapra, R.D. Goldman, and O. Medalia. 2017. The molecular architecture of lamins in somatic cells. Nature. 543:261-264.

Wazir, U., M.H. Ahmed, J.M. Bridger, A. Harvey, W.G. Jiang, A.K. Sharma, and K. Mokbel. 2013. The clinicopathological significance of lamin $A / C$, lamin $B 1$ and lamin $B$ receptor mRNA expression in human breast cancer. Cell Mol Biol Lett. 18:595-611.

Weigelin, B., Bakker, G.J., Friedl, P. 2012. Intravital third harmonic generation microscopy of collective melanoma cell invasion -Principles of interface guidance and microvesicle dynamics. IntraVital 1:1-12.

Wolf, K., I. Mazo, H. Leung, K. Engelke, U.H. von Andrian, E.I. Deryugina, A.Y. Strongin, E.B. Brocker, and P. Friedl. 2003. Compensation mechanism in tumor cell migration: mesenchymalamoeboid transition after blocking of pericellular proteolysis. The Journal of cell biology. 160:267-277.

Wolf, K., M. Te Lindert, M. Krause, S. Alexander, J. Te Riet, A.L. Willis, R.M. Hoffman, C.G. Figdor, S.J. Weiss, and P. Friedl. 2013. Physical limits of cell migration: control by ECM space and nuclear deformation and tuning by proteolysis and traction force. J Cell Biol. 201:1069-1084.

Wolf, K., Y.I. Wu, Y. Liu, J. Geiger, E. Tam, C. Overall, M.S. Stack, and P. Friedl. 2007. Multi-step pericellular proteolysis controls the transition from individual to collective cancer cell invasion. Nat Cell Biol. 9:893-904.

Xia, Y., I.L. Ivanovska, K. Zhu, L. Smith, J. Irianto, C.R. Pfeifer, C.M. Alvey, J. Ji, D. Liu, S. Cho, R.R. Bennett, A.J. Liu, R.A. Greenberg, and D.E. Discher. 2018. Nuclear rupture at sites of high curvature compromises retention of DNA repair factors. J Cell Biol. 217:3796-3808.

Yadav, S.K., S.W. Feigelson, F. Roncato, M. Antman-Passig, O. Shefi, J. Lammerding, and R. Alon. 2018. Elevated nuclear lamin $A$ is permissive for granulocyte transendothelial migration but not for motility through collagen I barriers. J Leukoc Biol.

Zwerger, M., D.E. Jaalouk, M.L. Lombardi, P. Isermann, M. Mauermann, G. Dialynas, H. Herrmann, L.L. Wallrath, and J. Lammerding. 2013. Myopathic lamin mutations impair nuclear stability in cells and tissue and disrupt nucleo-cytoskeletal coupling. Hum Mol Genet. 22:2335-2349. 


\section{This figure is in the process of being updated!}

A

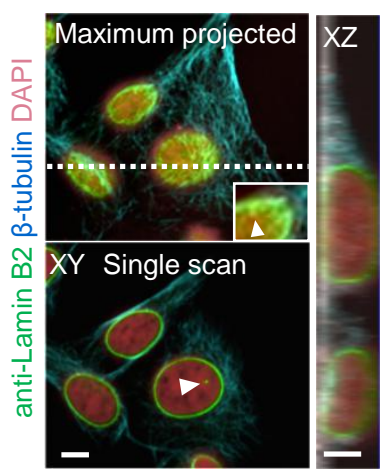

B

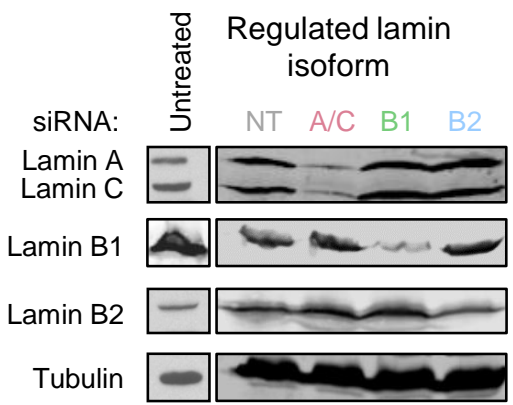

Transient lamin downregulation

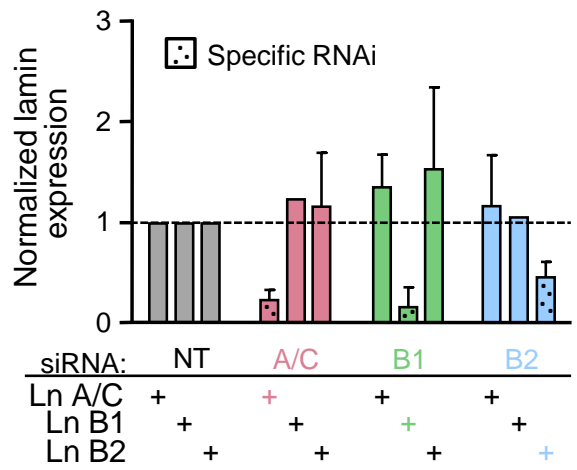

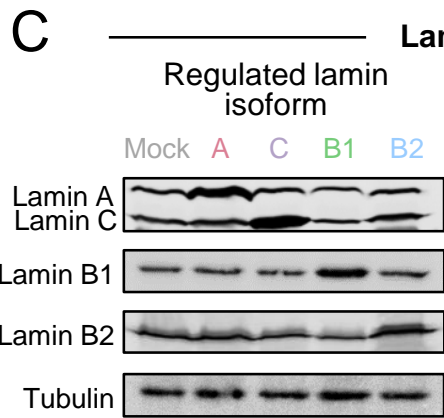

Lamin overexpression (OE)

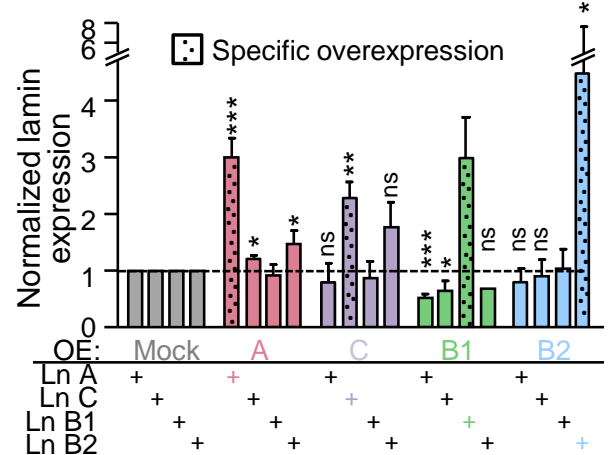

D

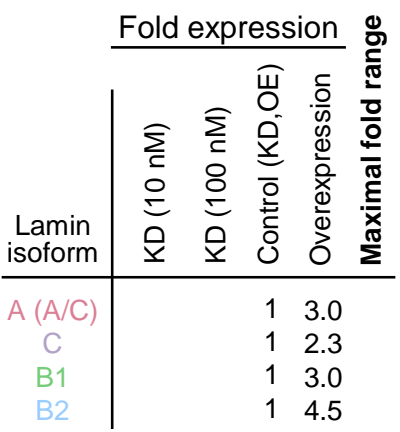

Figure 1. Transient knockdown or stable overexpression of lamin isoforms in HT1080 cells. (A) Lamin localization in cells shown in XY and XZ presentation. Upper left panel; maximal Z-projection to show overall lamin content. Lower left; single, central slice to visualize lamin ring from nuclear rim, and linear and dot-like lamin signals indicating tube-like invaginations (arrowheads). Right panel; XZ representation, created along white dotted line from upper left image for vertical view. Colored staining as indicated. Image bars: $5 \mu \mathrm{m}$. (B,C) Modification of lamin levels after transient knockdown (48h; $10 \mathrm{nM}$ RNAi) or stable overexpression of specific lamin isoforms. From laminspecific bands from the western blots (left), respective signal intensity was calculated by densitometry. Lamin intensity rates were normalized to both control (non-targeting control, NT; Mock) signal and respective tubulin loading control, and normalized controls are shown as 1 (graph; right). Lamin isoform-specific bands after indicated modification and respective matching antibody were quantified and shown as bars with dots and marked in color below the graph. Bars and whiskers are mean $+S D / S E M$. (B) $N=2-6$; (C) $n=2-5$. For statistical analyses, two-tailed unpaired Students t-test was used; ***, $\mathrm{P} \leq 0.001 ;{ }^{* *}, \mathrm{P} \leq 0.01 ;{ }^{*}, \mathrm{P} \leq 0.05 ; \mathrm{ns}$, non significant. (D) Mean lamin regulation level (deviating from 1 for NT or Mock) after indicated modulation of lamin isoforms. Data are a summary from Figs. 1, S1B, and not shown ( $\mathrm{n}=\mathrm{x}$ ). $\mathrm{KD}$, knockdown. 

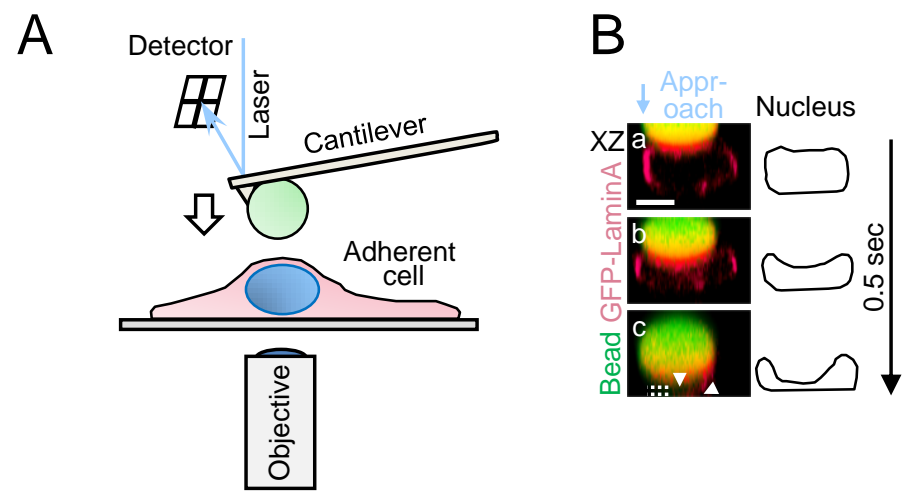

C
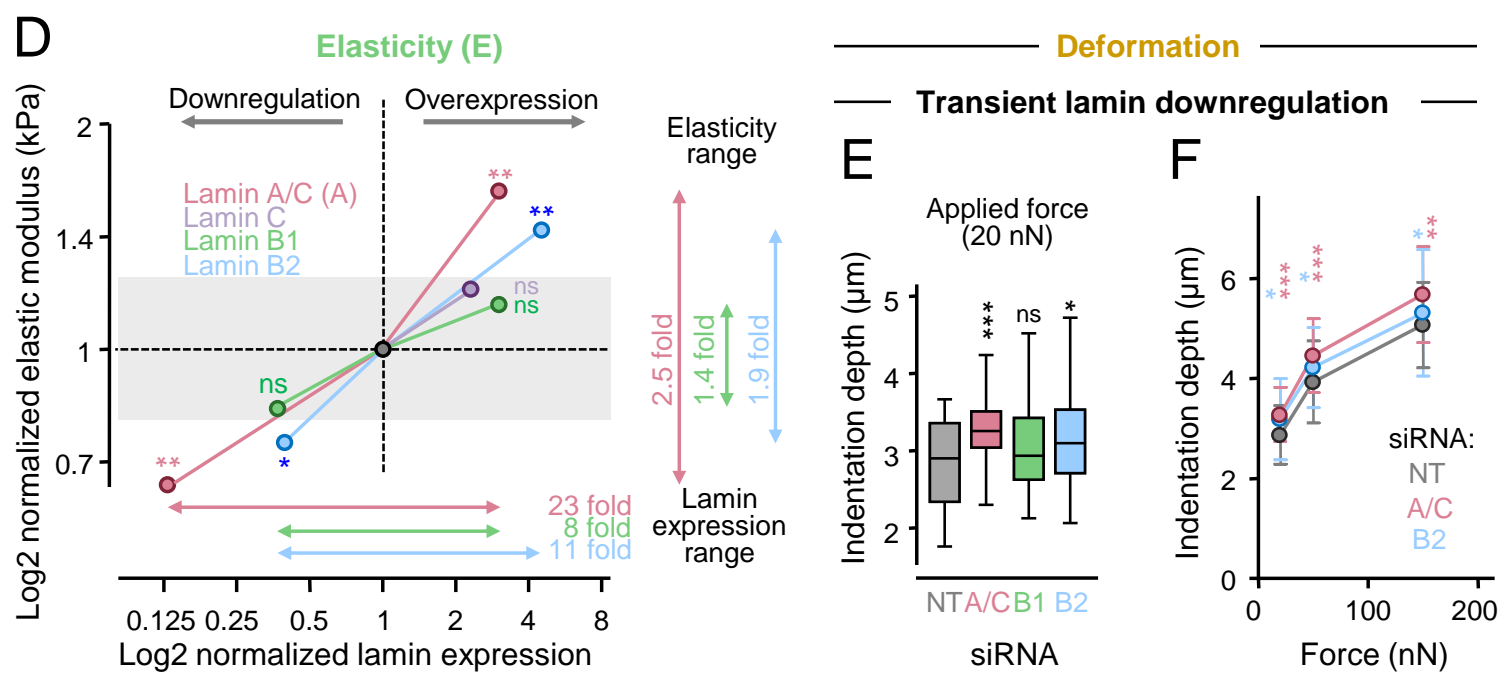

Micropipette assay
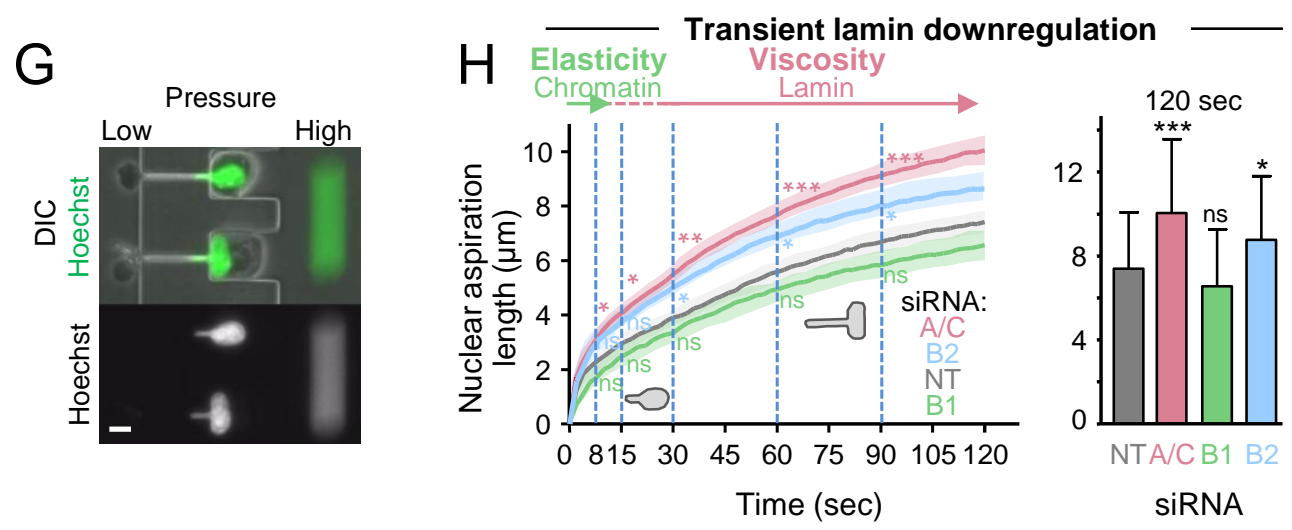

Figure 2. Mechanics of tumor cell nuclei correlates with expression of lamins A/C and B2. (A) Depiction of AFS methodology. (B) Visualization of nuclear compression of an adherent cell upon probing by a bead-coupled cantilever. XZ image sequence (corresponding to Video 1) of HT1080 cell stably expressing GFP-lamin A before (panel a) or during (panel b-c) application of $700 \mathrm{nN}$ force by a cantilever-coupled bead, with dotted lines and white arrowheads indicating respective nuclear heights. Numbers, time in seconds. Of note, compression was carried out at slower speed and with higher contact force, in order to visualize the measurement principle. Image bar, $10 \mathrm{~mm}$. (C) Nuclear penetration as a function of contact force measured by bead modified cantilevers as indicated. Black arrowheads indicate contact forces used in Fig. 2F. (D-H) HT1080 cells were treated by specific indicated siRNA's $(10 \mathrm{nM})$, or stably overexpressed with mock or lamin-specific vectors, and investigated either by AFS (D-F) or microaspiration (G,H). (D) Summary of elastic modulus measurements after indicated lamin modulation. Data points depict the normalized medians from elastic modulus measurements shown in Fig. S2 (with indicated P values), plotted against lamin expression values (from Fig. 1D). All data are depicted as ratio to normalized control (black point) on a double logarithmic (basis 2) scale. (E) Indentation at $20 \mathrm{nN}$ compression force after depletion of indicated lamin isoforms. (F) Indentation at 20, 50 and $150 \mathrm{nN}$ compression force after depletion of indicated lamin isoforms. (G) Representative image (from Video 2) of HT1080 cells treated with non-targeting control siRNA in the micropipette microfluidic device. Application of high pressure on one side of the device induces aspiration forces towards the respective other side of the device, with gradual pulling of cells and nuclei through $15 \mathrm{~mm}^{2}$ cross-sectioned channels over time. DNA was stained with Hoechst 33342. Image bar, $10 \mu \mathrm{m}$. (H) Left graph, averaged nuclear deformation length ( \pm SEM; shaded area) over time after siRNA mediated knockdown. Significance was calculated after 8, 15, 30, 60 and $90 \mathrm{sec}$. Right graph, bars (mean) + SD after $120 \mathrm{sec} . \mathrm{N}=3,24-41$ cells per condition. For all experiments, ${ }^{* *}, \mathrm{P} \leq 0.001 ;{ }^{* *}, \mathrm{P} \leq 0.01 ;{ }^{*}, \mathrm{P} \leq 0.05 ; \mathrm{ns}$, non significant. (D-F) Non-paired Mann-Whitney test, 
A

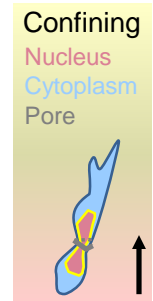

$5-25$

NonConfining (Optimal)

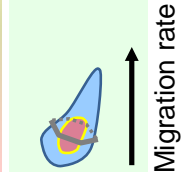

50-150

Pore area range $\left(\mu \mathrm{m}^{2}\right)$

$\mathrm{B}$

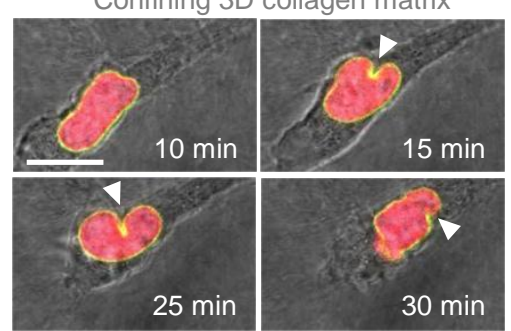

GFP-lamin A H2B-mCherry Brightfield

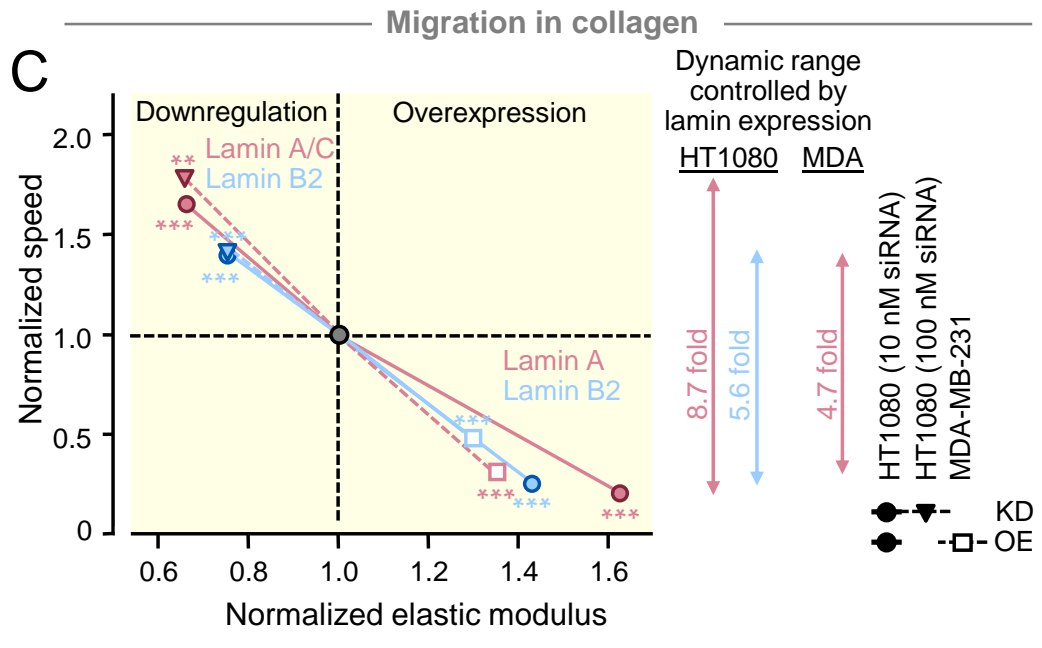

Figure 3. HT1080 tumor cell migration rates through dense collagen lattices inversely correlate with nuclear elasticity. (A) Scheme for classification of physical space into 'confining' or 'non-confining' (also 'optimal') pore areas relative to cell size, corresponding nuclear deformation, and migration capacity in collagen lattices. Whereas optimal pore sizes naturally match cross sections of proteolytically migrating cells and their ellyptic nuclei, confining pores induce dynamically adapting deformed nuclear shapes, leading to cell locomotion that is delayed by around half (visualized by arrow lengths; Wolf et al., 2013). Yellow/ red and green background coloring is used for the respective space conditions 'confining/ very confining' or 'optimal' in all following figures panels. (B) Sequence of cell expressing H2BmCherry and GFP-lamin A migrating in confining collagen in the presence of GM6001 at indicated time steps (corresponding to Video 3 ). Arrowheads point to confined locations of the nucleus. Image bar, $10 \mu \mathrm{m}$. (C) Medians of migration rates from 3D confining collagen were plotted against medians of the elastic modulus measured from indicated cell lines after respective lamin modulation and as compared to normalized control (black circle). Values are from Figs. S2; S3E,F; and S4B,D. P values are indicated for migration rates, whereas non-significant elasticity values are underlaid by gray area. KD, knockdown; $\mathrm{OE}$, overexpression. 

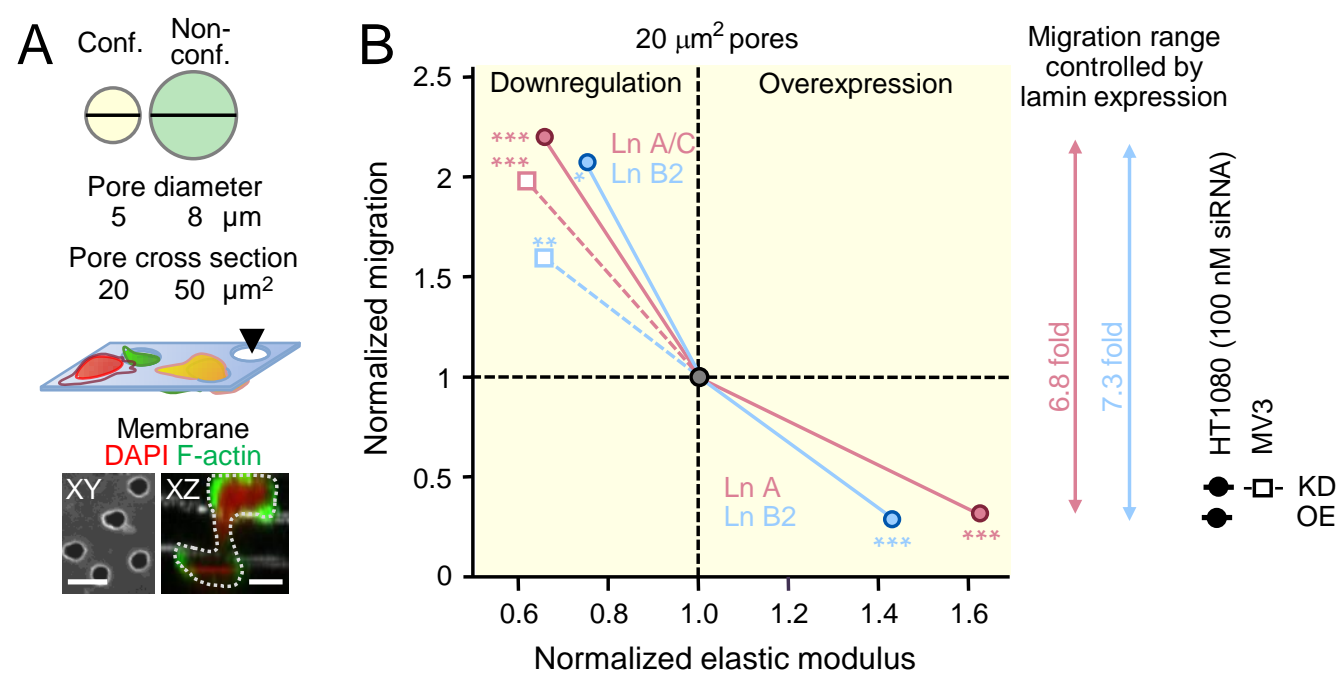

\section{Transient lamin downregulation}

\section{Migration in microchannel device}
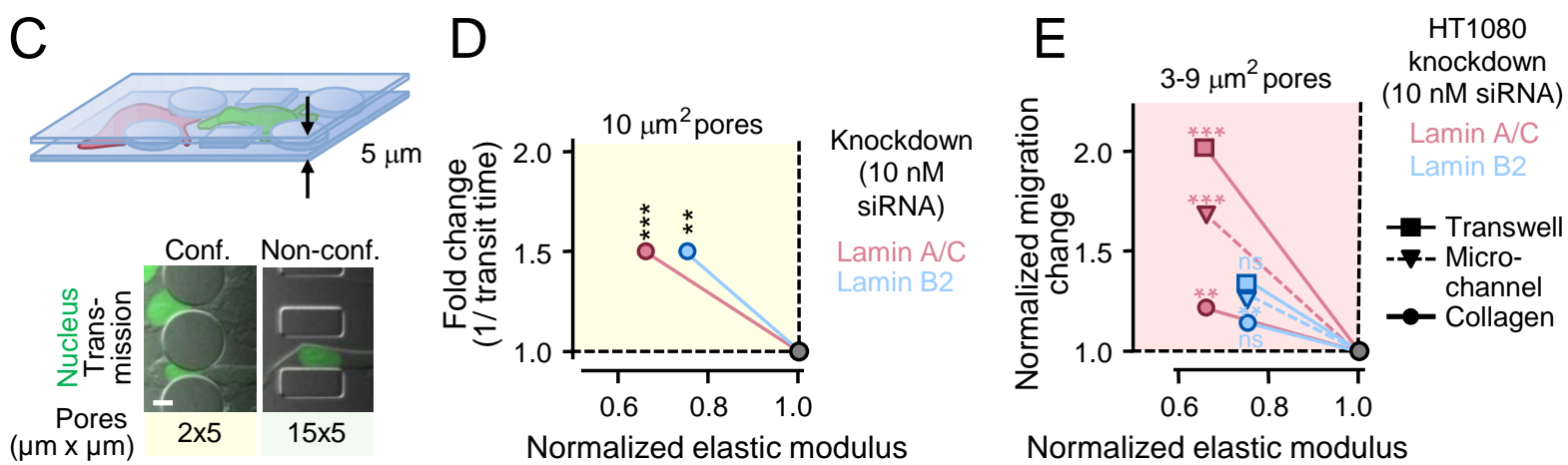

Figure 4. Migration rates in synthetic substrates of defined pore size. HT1080 cells were modulated for lamin expression as indicated and allowed to migrate through Boyden transwell chambers (A-B) or microchannels (C-D). (A) Scheme of used transwell pore sizes (upper panel) and transmigrating cells (middle). Conf., confining; Non-conf., non-confining. Bottom left, $\mathrm{XY}$ confocal depiction a transwell membrane containing $5 \mathrm{~mm}$ diameter pores; bottom right, $\mathrm{XZ}$ representation of deformed HT1080 cell (dotted outline) transmigrating a confining pore. (B) Migration rates through $5 \mathrm{~mm}$ diameter transwell pores plotted against elastic modulus measured from indicated cell lines after respective lamin modulation and compared to control (black circle). Values are the medians from Figs. S2; S3B,C; and S5A,B, and P values are indicated for transmigration rates. (C,D) Migration through microchannels. (C) Top, scheme depicting cells that migrate through the pores of the device; bottom, images of cells in the moment of transmigration through a $10 \mu \mathrm{m}^{2}$ constriction or an unconstricted $75 \mu^{2}$ channel (corresponding to Video 6). Nuclei are visualized through cell transfection with NLS-GFP. (D) Fold-decreased pore transit times through $2 \times 5 \mathrm{~mm}$ diameter pores plotted against elastic modulus (dots depict the medians from Figs. S2A and S5C) measured after knockdown of indicated lamin isoforms as compared to control (black circle). P values are from transit times (here depicted as $1 /$ transit time resulting in increased values for faster pore transition). (E) Comparsion of HT1080 cell migration efficacies after downregulation of indicated lamin isoforms at near-limiting $(3-9 \mathrm{~mm} 2)$ pore conditions from the different migration models (depicted are the medians from Figs. S2A and S5E,F,G; also note MDA-MB-231 cell migration data through the microchannel device in Fig. S5H). P values are indicated for (trans)migration rates. ${ }^{* * *}, \mathrm{P}<0.001 ;{ }^{* *}, \mathrm{P}<0.01 ;{ }^{*}, \mathrm{P}<0.05 ; \mathrm{ns}$, non-significant). (B,D,E) All non-significant elasticity values are underlaid by gray area. All image bars, $10 \mu \mathrm{m}$. 
$\mathrm{Oh}$

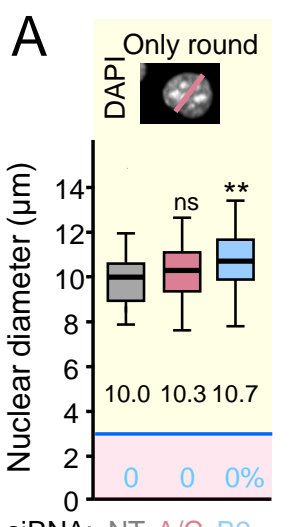

siRNA: NT A/C B2

Lamin isoform
B

Nuclear morphologies

during

Non-targeted

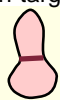

Lamin

O

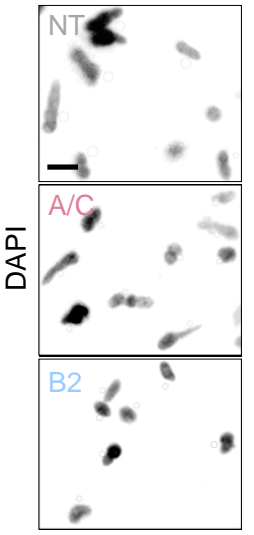

C

All migrating
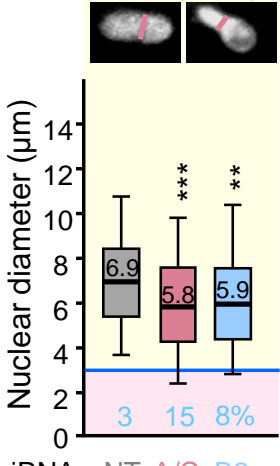

siRNA: NT A/C B2
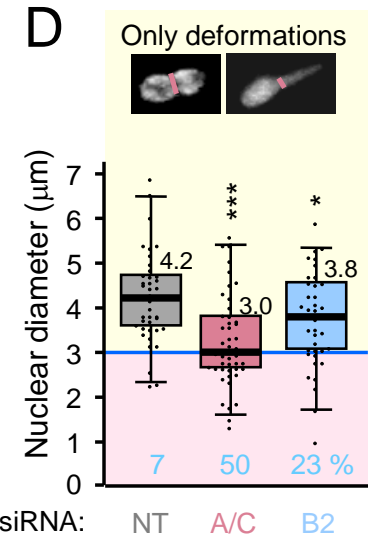

Regulated lamin isoform

Figure 5. Reduced nuclear diameters after lamin downregulation during HT1080 cell migration in dense

collagen. After treatment with non-targeting or lamin-specific siRNA, all cells were cultured in collagen (rat tail, $1.7 \mathrm{mg} / \mathrm{ml}$ ) in the presence of GM6001. (A) Diameters of individual cell nuclei, measured from DAPI signal as indicated by the red lines in the example images (top panels) immediately after collagen polymerization. (B) Left, scheme of typical nuclear shapes developing during migration in confinement; red lines, 'minimal' nuclear diameters. KD, knockdown. Right, representative images of nuclear morphologies after $15-20 \mathrm{~h}$ migration. Lattices were fixed, stained, and imaged for DAPI (together with phalloidin fluorescence and transmission signal for intact cell morphology, not shown), and confocal z-scans were maximally projected. Image bars, $10 \mathrm{~mm}$. (C,D) Diameters of individual cell nuclei.after $15-20 \mathrm{~h}$ migration. $(A, C, D)$ Horizontal lines, boxes and whiskers show the medians, $25^{\text {th }} / 75^{\text {th }}$, and $5^{\text {th }} / 95^{\text {th }}$ percentile. ${ }^{* * *}, \mathrm{P}<0.001 ; * *, \mathrm{P}<0.01 ; *, \mathrm{P}<0.05 ; \mathrm{ns}$, non-significant (non-paired Mann-Whitney test). Red areas with blue horizontal line in the lower part of the graphs, and numbers (in \%) depict the range and percentage of nuclei at or below $3 \mathrm{~mm}$ diameter. Black numbers in graphs indicate median nuclear diameters. (A) $\mathrm{N}=2$ $3 ; 48-81$ cells; (C) $n=2 ; 80-120$ cells; (D) $n=3 ; 36-46$ cells per condition. 
A

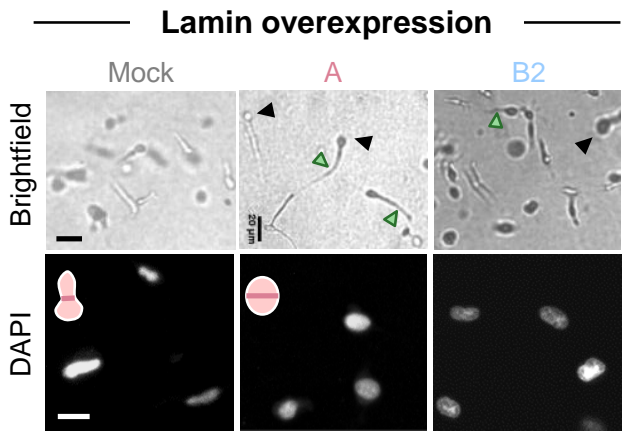

B
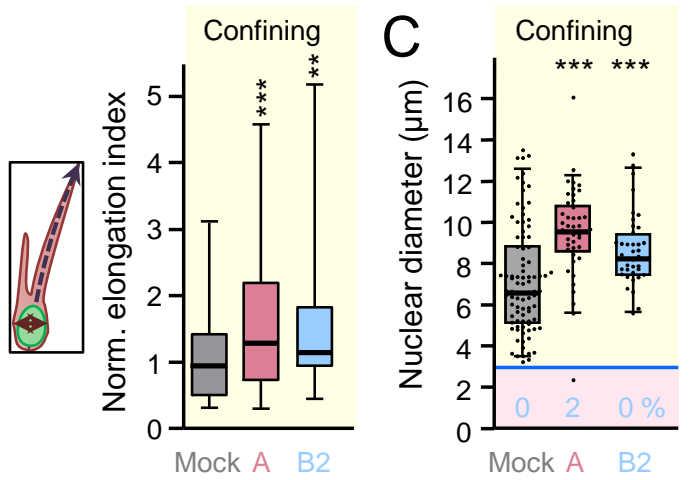

Regulated lamin isoform
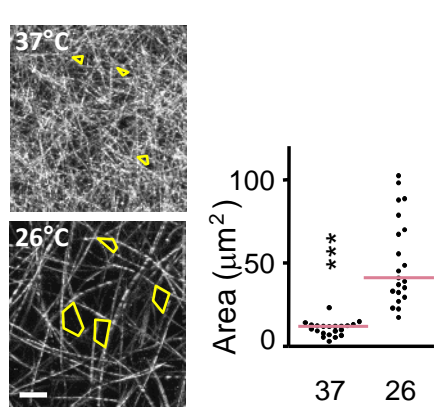

Collagen polymerization temperature $\left({ }^{\circ} \mathrm{C}\right)$

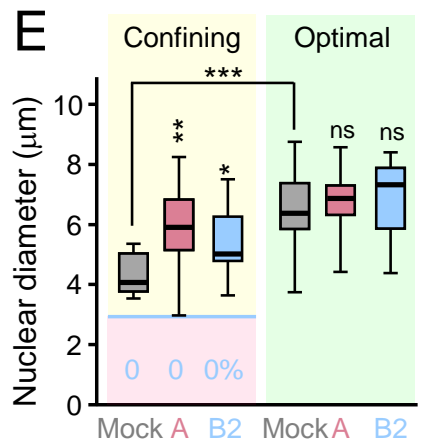

Regulated lamin isoform $-37^{\circ} \mathrm{C}--26^{\circ} \mathrm{C}-$

\section{F}
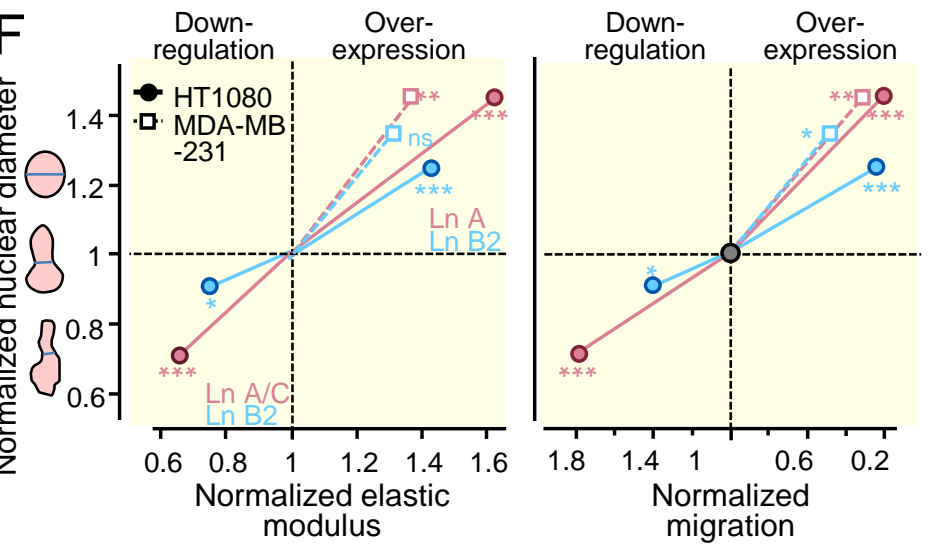

Figure 6. Elongated cell shapes and rounded nuclei during migration in dense collagen after lamin upregulation. (A-C) HT1080 or (E) MDA-MB-231 cells were stably transduced with control or indicated lamin vectors and migrated within rat tail (A-C) or bovine (E) collagen $(1.7 \mathrm{mg} / \mathrm{ml}$; unless indicated otherwise) in the presence of GM6001 for 15-20 h. (A) Top row, representative brightfield images of cells with indicated lamin modulations after migration in collagen for $10 \mathrm{~h}$ (corresponding to Video 5). Black arrowheads, round cell rears indicative of nuclear position; green arroheads, elongated cell protrusions. Bottom row, representative maximum projected DAPI images from nuclei of migrating cells. (B) Cell elongation. Left, schematic depiction of calculated elongation index measured as cell body length divided by cell body width. Right, quantified normalized nuclear elongation index from cells as shown in A). $\mathrm{N}=2-4 ; 41-125$ cells per condition. (C) Quantification of minimum nuclear diameters as shown in A. N = 1-6; 24-90 cell nuclei per condition, shown as dots. (D) Left, bovine collagen lattices of 2.5 and $1.7 \mathrm{mg} / \mathrm{ml}$, and at $37^{\circ} \mathrm{C}$ and $26^{\circ} \mathrm{C}$ polymerization temperatures, respectively, imaged by confocal reflection microscopy, with depiction of pore areas (yellow outline). Right, pore area quantification. (E) Minimum nuclear diameters after MDA-MB-231 migration for $20 \mathrm{~h}$ in collagen polymerized at indicated temperatures. 8-26 cells per condition. (F) Correlation of normalized nuclear diameters in confinement plotted against elastic modulus (left) or migration rates (right). Dots are the medians from Figs. 5F; 6C; S2; S4B,D (HT1080); 6E and S3E,F (MDA-MB-231). $\mathrm{P}$ values are from the calculation of nuclear diameters, and all nonsignificant elasticity values are underlaid by gray area. The nuclear deformation range during migration by experimental lamin modulation is indicated on the right. $(C, E)$ Red areas with blue horizontal lines in the lower parts of the graphs mark $\leq 3 \mathrm{~mm}$ nuclear diameter ranges. Numbers in blue, percentages of cell nuclei below $\leq 3 \mathrm{~mm}$. (B,C,E) Horizontal lines, boxes and whiskers show the medians, $25^{\text {th }} / 75^{\text {th }}$, and $5^{\text {th }} / 95^{\text {th }}$ percentile. ${ }^{* * *}, \mathrm{P}<0.001 ;{ }^{* *}, \mathrm{P}<0.01 ; *, \mathrm{P}<0.05$; ns, non-significant (non-paired Mann-Whitney test). Image bars, $20 \mu \mathrm{m}$ (A, upper row); $10 \mu \mathrm{m}$ (A, lower row; D).
HT1080 nuclear diameter arange 
A

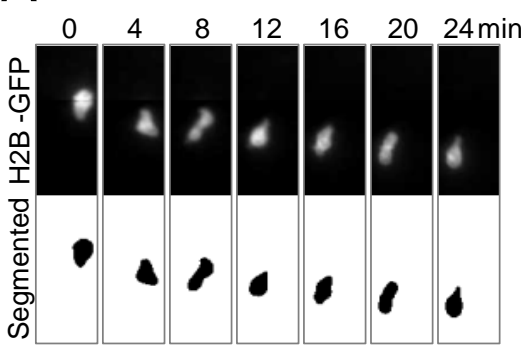

B Nuclear fluctuation

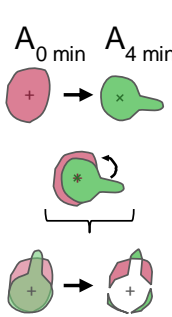

Transient lamin downregulation

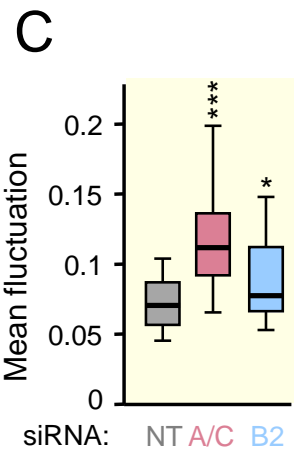

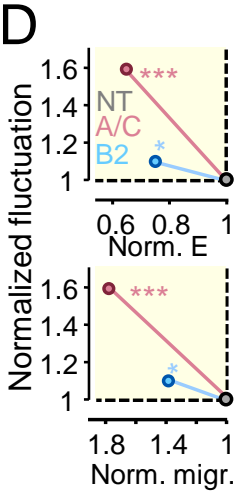

Figure 7. Increased nuclear shape change during migration in small spaces after lamin

downregulation. HT1080 cells stably expressing H2B-GFP and migrating at confining conditions (rat tail collagen; 1.7 $\mathrm{mg} / \mathrm{ml}$, in the presence of GM6001) were imaged by dynamic spinning disk microscopy for changes in nuclear morphology and analyzed. (A) Representative image sequence of a nucleus during cell movement (upper row), that remained in focus and was thresholded and segmented for further analysis (bottom row; corresponding to Video 9). (B) Depiction of analysis principle of nuclear fluctuation. Nuclear areas A from 2 consecutive time points, having developed different shapes (upper row), were overlaid at the center (cross) and rotated for maximal overlap (middle row; indicated by bended arrow) to remove errors by changes in step angle during the migration process from analysis. The lack of overlap was calculated as remaining pixel difference (colored areas) between two time points. (C) Mean values of the fluctuations from each nuclear shape to the next per cell migration sequence after indicated control and silamin treatments, calculated as stated in method section. A fluctuation value of 0 is equal with a complete overlap, and a (theoretical) value of 1 means no overlap at all. $\mathrm{N}=3-4$; 18-32 cells per condition. Horizontal lines, medians; box plots, $25^{\text {th }}$ to $75^{\text {th }}$ percentile; and whiskers, $5^{\text {th }}$ to $95^{\text {th }}$ percentile. For all experiments, non-paired Mann-Whitney test was used for statistical analysis. ${ }^{* *}, \mathrm{P}<0.001 ;{ }^{* *}, \mathrm{P}<0.01 ;{ }^{*}, \mathrm{P}<0.05$; ns, non-significant. (D) Fluctuation plotted against elasticity and migration after depletion of indicated lamin isoforms. Dots depict the medians from Figs. S2A, S4B and 7C, and P values are from Fig. 7C. 


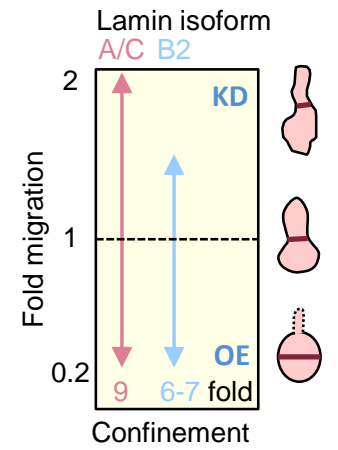

Figure 8. Lamin A/C and B2 expression determines nuclear deformation and cell migration efficacy in

dense 3D environments. Left, summary on the impact of lamin expression regulation on relative migration efficacy at confining pore size. Migration of cells not modulated for lamin expression is set to 1 . Right, respective nuclear shapes and diameters (brown line) concordant to lamin expression level during migration in confinement. $\mathrm{KD}$, lamin knockdown; $\mathrm{OE}$, lamin overexpression. 


\section{This table is in the process of being updated!}

\begin{tabular}{|c|c|c|c|c|c|c|c|c|c|c|c|}
\hline & \multicolumn{4}{|c|}{$\begin{array}{l}\text { Lamin } \\
\text { upwnregulation }\end{array}$} & \multirow{2}{*}{$\frac{\text { 上 }}{\text { 竞 }}$} & \multicolumn{6}{|c|}{$\begin{array}{c}\text { Lamin } \\
\text { downregulation } \\
\text { (10 nM siRNA) }\end{array}$} \\
\hline & A & I C & B1 & I B2 & & $\mathrm{A} / \mathrm{C}$ & i & B1 & i & B2 & $\mathrm{A} / \mathrm{C}+\mathrm{B} 2$ \\
\hline & & 1 & $\mathbf{I}$ & $\mathbf{I}$ & & & 1 & & I & & I \\
\hline Expression & & i & i & i & & & i & & i & & i \\
\hline Western blot & & I & $\mathbf{I}$ & $\mathbf{I}$ & & & 1 & & i & & i \\
\hline---------- & & 1 & $1-2$ & $\begin{array}{c}1 \\
-1-2\end{array}$ & 1 & 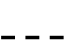 & 1 & --- & 1 & -- & 1 \\
\hline Nuclear & & 1 & $i^{-2-}$ & 1 & & & 1 & & $\vec{i}$ & & 1 \\
\hline mechanics & & 1 & I & $\mathbf{I}$ & & & I & & I & & $i$ \\
\hline Elasticity & & 1 & I & I & 1 & & I & & I & & 1 \\
\hline (AFM) & & I & i & I & 1 & & I & & I & & 1 \\
\hline (ArIVI) & & 1 & i & i & 1 & & i & & i & & i \\
\hline Deformation & & 1 & $\mathbf{I}$ & $\mathbf{I}$ & & & I & & I & & I \\
\hline (AFM) & & I & I & I & 1 & & I & & I & & I \\
\hline Nuclear strain & & $\mathrm{i}$ & $\mathrm{i}$ & $\mathrm{i}$ & 1 & & I & & I & & $\mathrm{I}$ \\
\hline & & I & I & i & 1 & & i & & i & & $\mathrm{i}$ \\
\hline Deformation & & 1 & I & I & & & I & & I & & I \\
\hline (Micropipette) & & I & I & I & 1 & & I & & 1 & & 1 \\
\hline 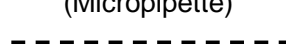 & & 1 & I & $\mathbf{I}$ & & & 1 & & I & & 1 \\
\hline $\bar{M}$ igration & & $\frac{1}{1}$ & $1-$ & - - & & -- & -ト & & 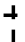 & -- & $-1---$ \\
\hline & & i & i & I & & & I & & i & & I \\
\hline Collagen & & I & I & I & 1 & & I & & I & & i \\
\hline Transwell & & 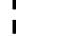 & i & 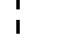 & 1 & & i & & i & & 1 \\
\hline $\begin{array}{l}\text { filter } \\
\text { fils }\end{array}$ & & i & i & i & 1 & & i & & i & & $\mathrm{i}$ \\
\hline milter & & 1 & I & I & 1 & & 1 & & I & & 1 \\
\hline Micro- & & $\mathrm{I}$ & I & I & 1 & & $\mathrm{I}$ & & 1 & & 1 \\
\hline $\begin{array}{l}\text { Micro- } \\
\text { channel }\end{array}$ & & I & I & I & 1 & & I & & I & & 1 \\
\hline - CIIIIIC- & & $r$ & $7-$ & r & - & & & & & - & $-1---$ \\
\hline Migration-related & & $\mathrm{i}$ & i & i & & & i & & i & & i \\
\hline nuclear shape & & $\mathrm{I}$ & I & I & & & I & & I & & 1 \\
\hline & & I & I & I & & & I & & I & & 1 \\
\hline Nuclear & & I & I & $\mathbf{I}$ & 1 & & I & & I & & I \\
\hline diameter & & I & I & I & 1 & & I & & I & & I \\
\hline & & $i$ & i & i & & & i & & i & & $\mathrm{i}$ \\
\hline Shape change & & $!$ & ! & $!$ & 1 & & ! & & ! & & ! \\
\hline
\end{tabular}

Table 1. Summary of all measured lamin-related changes shown in Figures 1-7. Displayed numbers are fold changes as compared to NT or Mock control in HT1080, MDA-MB231, MV3 and MCF-7 cells. Note that almost exclusively the fold changes for lamin B2 are closer to 1 than for lamin A/C, meaning that all effects mediated by lamin B2 are present but somewhat weaker than lamin A/C. 


\section{A}

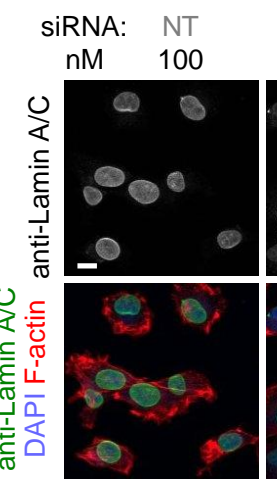

$\mathrm{A} / \mathrm{C}$

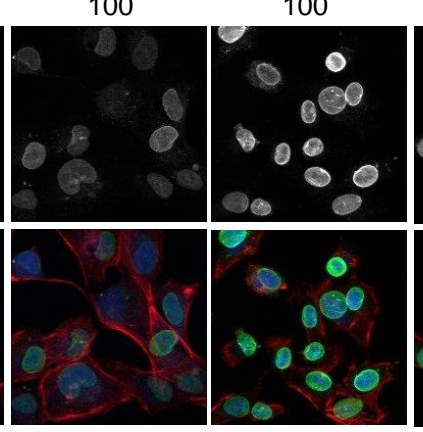

100

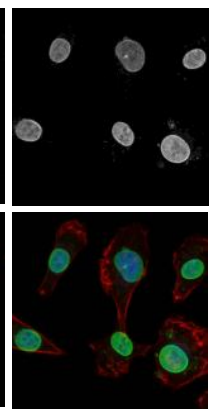

$\therefore$ Lamin A specific RNAi

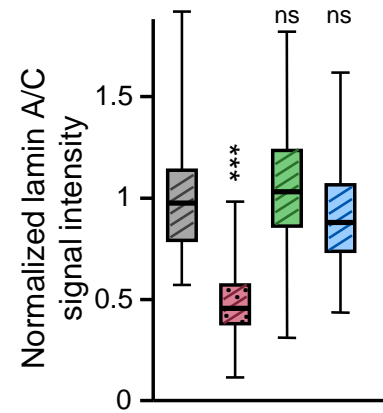

siRNA: NT A/C B1 B2

B

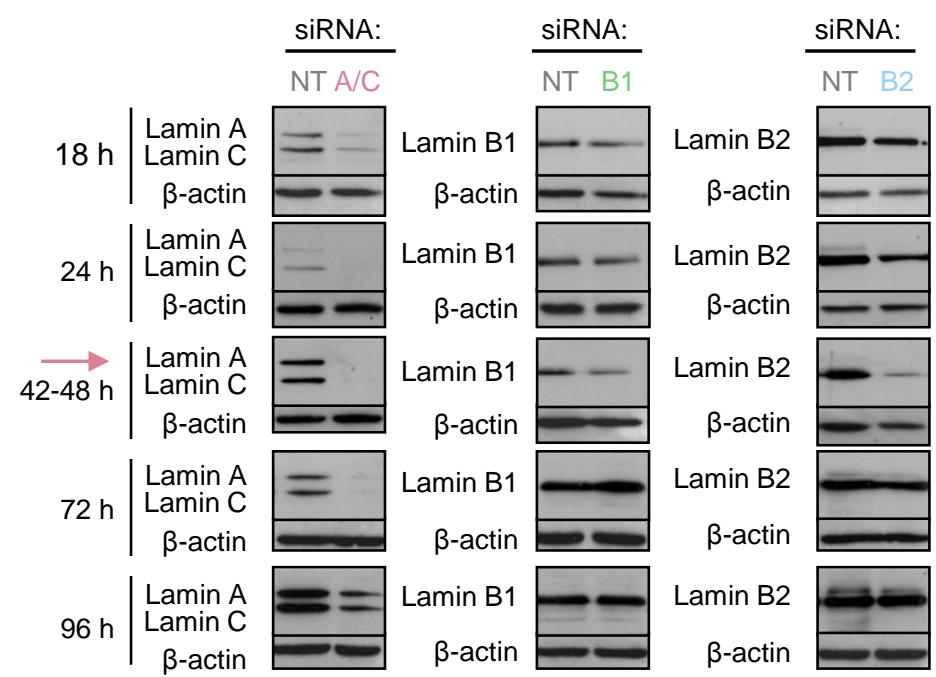

C

SiRNA: NT $\quad A / C$

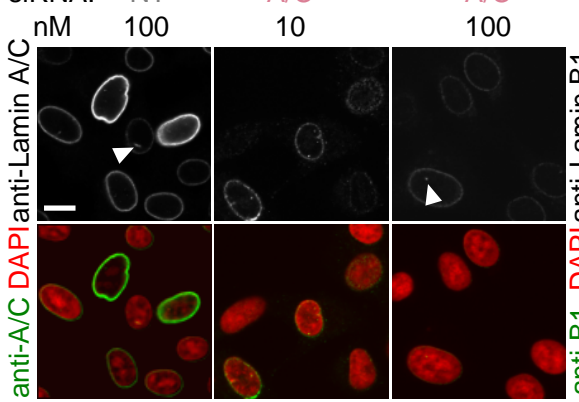

$\mathrm{A} / \mathrm{C}$

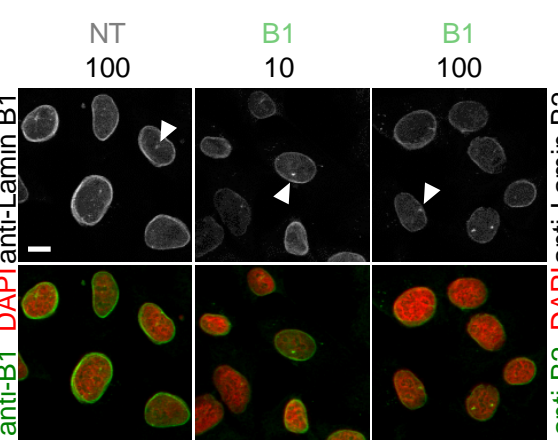

NT

100

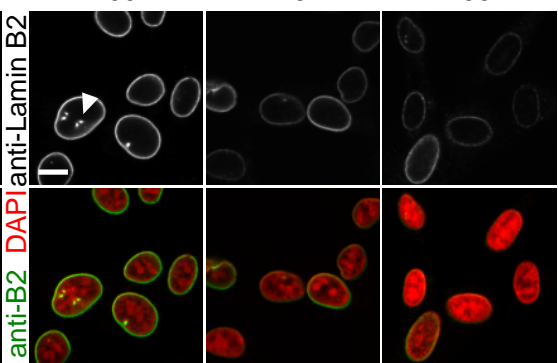

Lamin overexpression

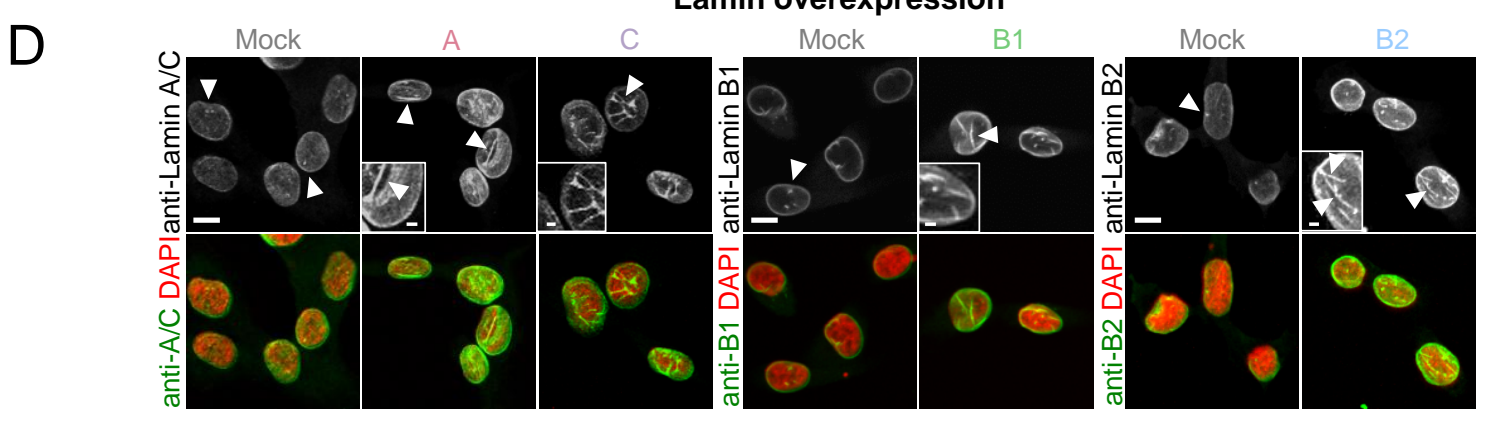

Figure S1. HT1080 cell lamin levels after expression modulation. Nuclear morphology and lamin localization and intensity after transient lamin downregulation or stable overexpression $(A, C, D)$. 2D cell cultures on glass were fixed by PFA $(A, D)$ or methanol $(C)$, stained and imaged by confocal microscopy. Images are displayed as single central Z-scans. (A) Lamin A/C intensity after transient downregulation by lamin-isoformspecific siRNA of each $100 \mathrm{nM}$; striped bars, as in all following data sets). Confocal imaging (left) and graph (right) for mean lamin intensity per nucleus $(n=1 ; 40-66$ cells per condition), as determined from images as shown left, but quantified from projections as shown in Fig. 1A. Black lines, boxes and whiskers; medians, $25^{\text {th }} / 75^{\text {th }}$, and $5^{\text {th }} / 95^{\text {th }}$ percentile. For statistical analyses, non-paired Mann-Whitney test was used. (B) Changes of lamin levels over indicated time periods after lamin downregulation; determined by western blot. Sample lysates were generated after indicated time points post transfection with $100 \mathrm{nM}$ siRNA. Lamin expression was found to be most reduced after $42-48 \mathrm{~h}$ (red arrow), and was $12-13 \%$ for lamin $\mathrm{A} / \mathrm{C}, 52 \%$ for lamin B1 and $20 \%$ for lamin B2, as compared to $100 \%$ lamin expression in non-targeting siRNA treated cells and normalized to $\beta$-actin protein content. (C) Representative images of lamin downregulation $48 \mathrm{~h}$ after transfection with 10 or $100 \mathrm{nM}$ siRNAs targeting indicated lamin isoforms. White arrowheads indicate intranuclear speckles. (D) Stable overexpression of indicated lamin isoforms, $24 \mathrm{~h}$ after cell seeding. White arrowheads indicate intranuclear speckles/ tubes or membrane foldings, respectively (also see insets). All image bars: $10 \mu \mathrm{m}$, except insets $(2 \mu \mathrm{m})$. 


\section{B \\ Stable lamin overexpression}
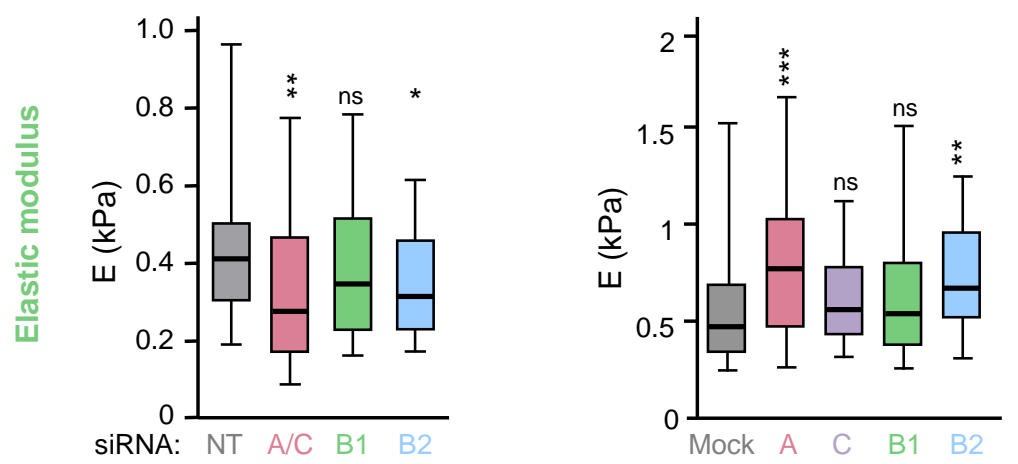

Regulated lamin isoform

Figure S2. AFS-derived elastic modulus of HT1080 cells after modulation of lamin expression. HT1080 cells were either treated by specific indicated siRNA's (10 nM; A) or stably overexpressed with lamin-specific or control vectors (B). Elastic modulus $E$ of cells after (A) lamin A/C, $B 1$ and $B 2$ siRNA treatment calculated from $0.5 \mathrm{nN}$ force curves; $\mathrm{n}=2-4 ; 28-66$ cells per condition, and (B) stable lamin overexpression calculated from $2 \mathrm{nN}$ force curves; $\mathrm{n}=2-5 ; 23-48$ cells per condition. To better compare experiments carried out on different days, medians from the individual non-targeted control cell populations were calculated (i.e. $0.50 ; 0.58 ; 0.62 ; 0.50$ ). Then one median (i.e. 0.53 ) was formed based on the data of all control cells. Subsequently, a correction factor for each experiment was calculated (i.e.1.06; 0.91; 0.86; 1.06) and applied for each measurement. Black horizontal lines, boxes and whiskers show the medians, $25^{\text {th }} / 75^{\text {th }}$, and $5^{\text {th }} / 95^{\text {th }}$ percentile. For all experiments, $* * *, P$ $<0.001 ;{ }^{* *}, \mathrm{P}<0.01 ;{ }^{*}, \mathrm{P}<0.05 ; \mathrm{ns}$, and non-significant (non-paired Mann-Whitney test). 

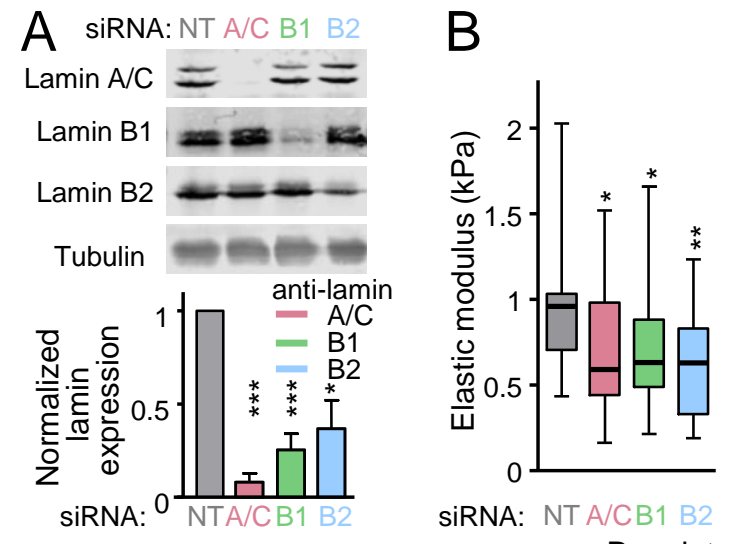

C Transwell filters

SiRNA: NT A/CB1 B2

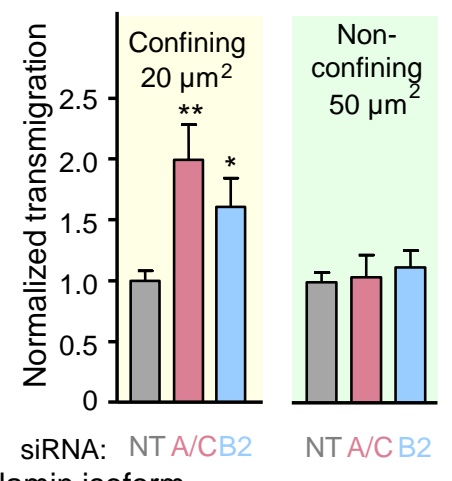

\section{Lamin overexpression in MDA-MB-231 cells}

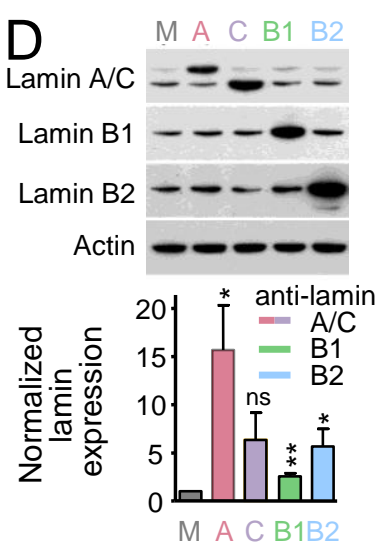

Lamin overexpression in MCF-10A cells

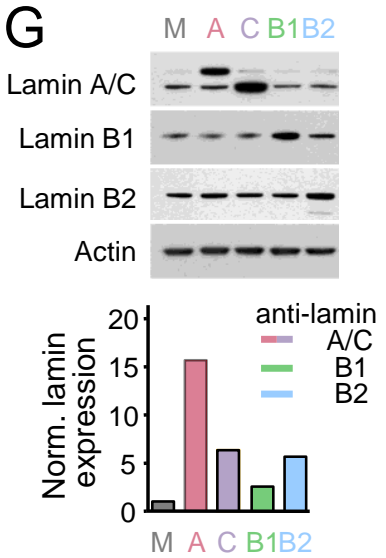

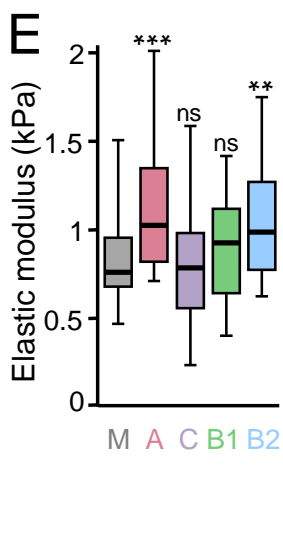

$\mathrm{H}$ Nuclear strain

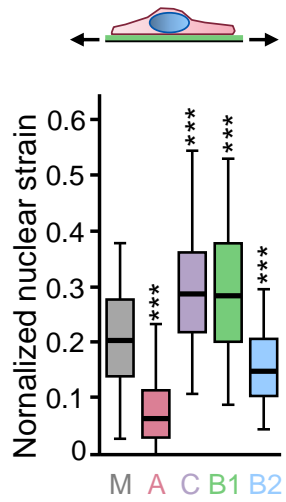

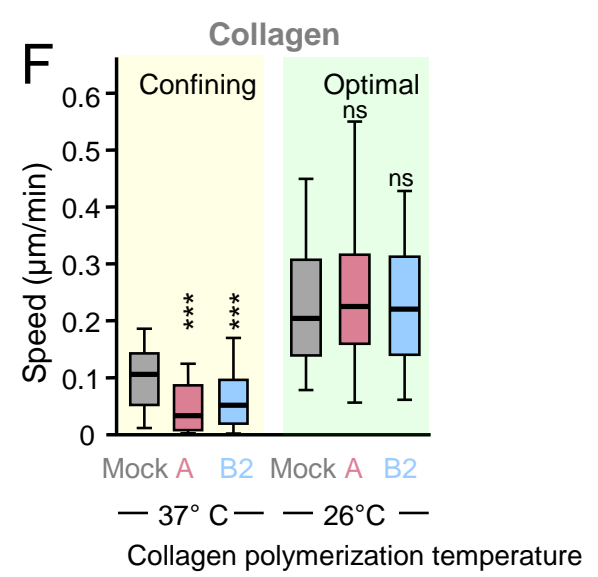

Figure S3. Measurements of laminmediated nuclear elasticity and migration rates in different cell types. MV3 melanoma cells were transfected with $10 \mathrm{nM}$ indicated laminspecific siRNAs before the experiment (A-C), and MDA-MB-231 (D-F) and MCF10A cells (GH) were stably transduced with vectors coding for indicated lamin isoforms. (A,D,G) Top, representative western blots for lamin A, C, B1 and B2 levels and tubulin or actin loading control from whole cell lysates. Bottom, expression levels of specifically regulated lamin isoforms after calculation of signal intensity by densitometry and normalization to both loading control and control siRNA transfection. $M$, Mock vector transduced control cells. Means and SEM are shown; $n=3$ $(A, D) ; n=1$ (G). (B) Elastic modulus of cells after indicated siRNA treatment. Cells were

probed with $1.5 \mathrm{nN}$ applied force and values were calculated into $\mathrm{E}$ in $\mathrm{kPa}$. $\mathrm{N}=2 ; 22-30$ cells per condition. (C) Normalized transmigration rates of cells that have successfully passed to the lower side of a $5 \mu \mathrm{m}$ or $8 \mu \mathrm{m}$ porous membrane, respectively. $\mathrm{N}=1-3$; bars represent mean and whiskers are SEM. (E) Elasticity measurements, calculated from $2 \mathrm{nN}$ force; $\mathrm{n}=2-3$; 30-35 cells per condition. (F) Averaged single cell migration rates over $24 \mathrm{~h}$ in collagen lattices of bovine origin polymerized at indicated temperatures (see Fig. 6D) and in the presence of GM6001; $n=1-3$, 28-107 cells per condition. $(\mathrm{H})$ Top, cartoon depicting the principle of nuclear strain measurements. Bottom, nuclear strain measurements from MCF10A cells adherent to... $N=\geq 3$; 124-157 cells per condition. (A,C,D,G) Bars and whiskers, mean and SEM; $(B, E, F, H)$ horizontal lines, boxes and whiskers showing the medians, $25^{\text {th }} / 75^{\text {th }}$, and $5^{\text {th }} / 95^{\text {th }}$ percentile. For all experiments, ${ }^{* * *}, \mathrm{P}<0.001 ; * *, \mathrm{P}<0.01 ;{ }^{*}, \mathrm{P}<0.05$; ns, non-significant; $(\mathrm{A}, \mathrm{C}, \mathrm{D})$ two-tailed unpaired Students t-test); (B,E,F,H) non-paired Mann-Whitney test. 


\begin{tabular}{c|c|c|c|c|c|c|c} 
A & $\begin{array}{c}\text { Collagen } \\
\text { type }\end{array}$ & Source & $\begin{array}{c}\text { Concen- } \\
\text { tration } \\
(\mathrm{mg} / \mathrm{ml})\end{array}$ & $\begin{array}{c}\text { Polym. } \\
\text { temp } \\
\left({ }^{\circ} \mathrm{C}\right)\end{array}$ & Cells & $\begin{array}{c}\text { GM } \\
6001\end{array}$ & \multicolumn{2}{|c}{ Median } & Range \\
\hline Rat tail & BD & 1.7 & 37 & + & + & 12 & $\mathbf{5 - 2 3}$ \\
Rat tail & BD & 1.7 & 37 & + & - & 100 & $\mathbf{5 1 - 1 4 9}$ \\
Bovine & Nutragon & 2.5 & 37 & - & - & 12 & $3-23$ \\
Bovine & Nutragon & 1.7 & 26 & - & - & 41 & $17-102$ \\
Rat tail & BD & 2.5 & 37 & + & + & 7 & $\mathbf{3 - 1 1}$ \\
Rat tail & Weiss lab & 1.7 & 37 & - & - & 4 & $2-12$ \\
Rat tail & BD & 1.7 & 37 & - & - & 12 & $5-29$ \\
Bovine & Nutragon & 1.7 & 37 & - & - & 19 & $8-46$
\end{tabular}

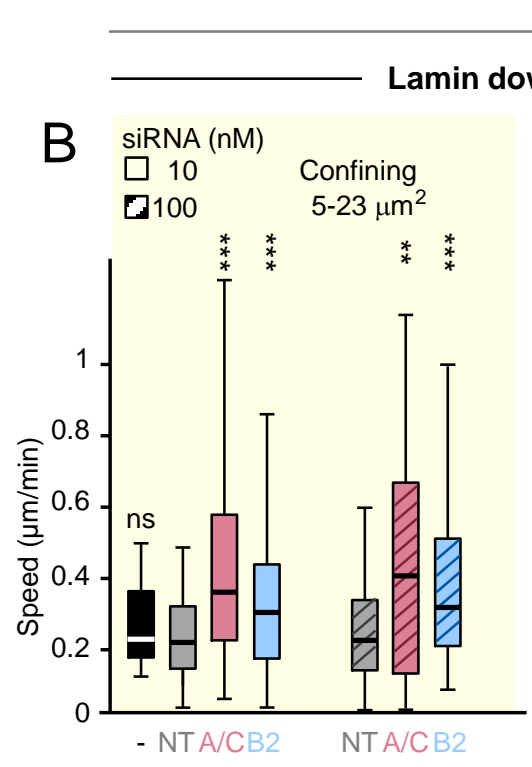

\section{Migration in collagen}

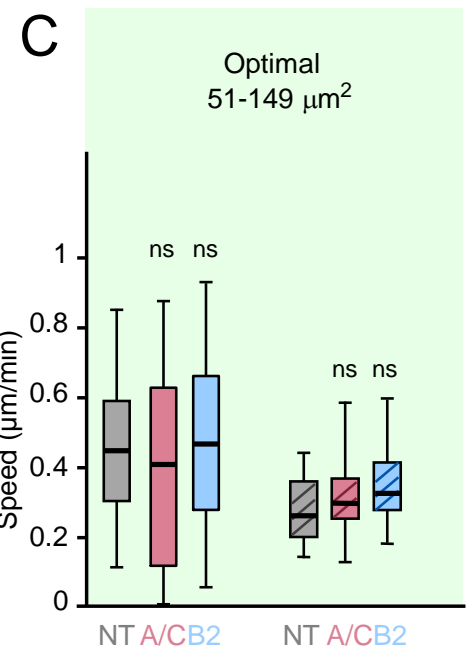

\section{Lamin overexpression}

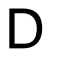

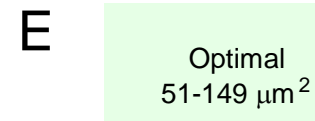

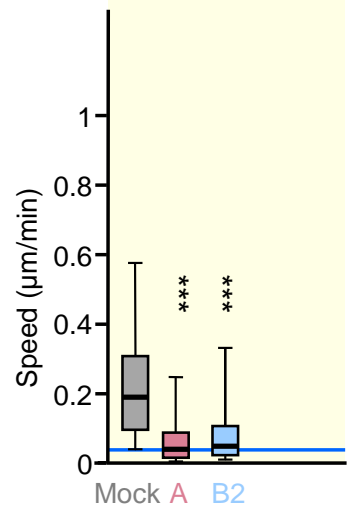

$51-149 \mu \mathrm{m}^{2}$

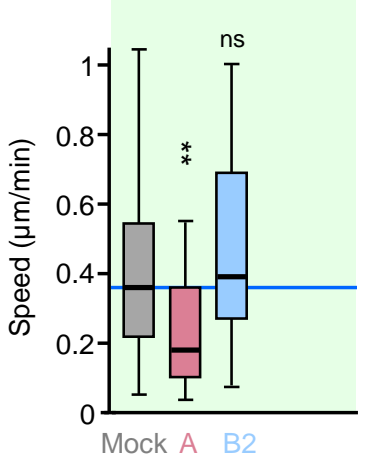

Regulated lamin isoform

\section{F Migration over glass}
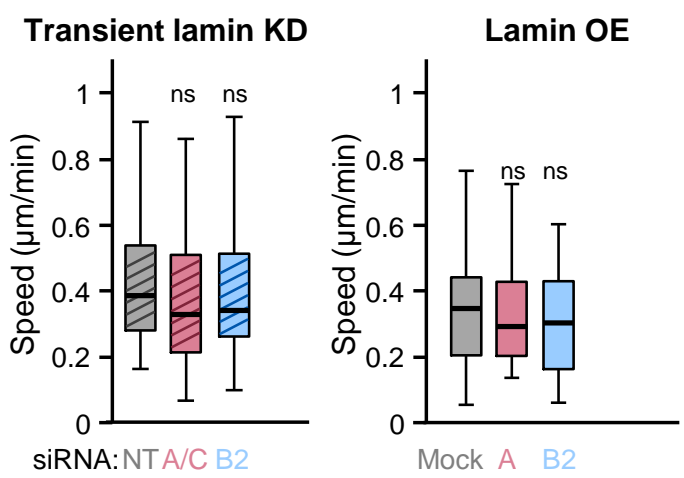

Regulated lamin isoform

Figure S4. Impact of lamin modulation on HT1080 migration rates in collagen of varying porosity or on glass. (A) Comparison of pore areas quantified from different indicated collagen sources and densities (see Denais et al., 2016; Wolf et al., 2013); 21 data points per condition. Colored areas indicate confining (yellow), non-confining (green) and (near-) limiting (red) pore conditions induced by different collagen concentrations, sources, and by the presence or absence of proteolysis during cell migration. (B-E) Cell migration in 3D collagen of indicated porosity monitored by time-lapse microscopy over 20-24 h. (B,C) Averaged single cell migration rates after transient downregulation by indicated concentrations of specific siRNA, analyzed by single-cell tracking. Cells migrated in rat tail collagen $(1.7 \mathrm{mg} / \mathrm{ml})$ in the presence (B) or absence (C) of GM6001. (D,E) Averaged single cell migration rates after stable overexpression of control or indicated lamin vectors. Cells migrated in rat tail collagen $(1.7 \mathrm{mg} / \mathrm{ml})$ in the presence (D) or absence (E) of GM6001. (F) Cell migration over the surface of a cell culture dish. Cells were monitored by time-lapse microscopy and analyzed by cell tracking. Averaged single cell migration rates after treatment with $100 \mathrm{nM}$ indicated specific siRNA's; or after stable expression by empty vector or indicated lamin isoforms. (B-F) Horizontal lines, boxes and whiskers show the medians, $25^{\text {th }} / 75^{\text {th }}$, and $5^{\text {th }} / 95^{\text {th }}$ percentile. (D,E) Horizontal blue lines mark $10 \%$ migration rates $(0.036 \mu \mathrm{m} / \mathrm{min})$ in confinement as compared to migration of Mock cells in optimized conditions (0.36 $\mu \mathrm{m} / \mathrm{min})$. (B) $N=2-5,52-166$ cells; (C) $n=2-3,16-31$ cells; (D) $n=3 ; 87-93$ cells; (E) $n=1-2,30-62$ cells; (F) $n=2,44-61$ cells (left graph); $\mathrm{n}=2$; 66-71 cells per condition (right graph). ${ }^{* *}, \mathrm{P}<0.001 ;{ }^{* *}, \mathrm{P}<0.01 ;{ }^{*}, \mathrm{P}<0.05 ; \mathrm{ns}$, non-significant; by non-paired Mann-Whitney test. 

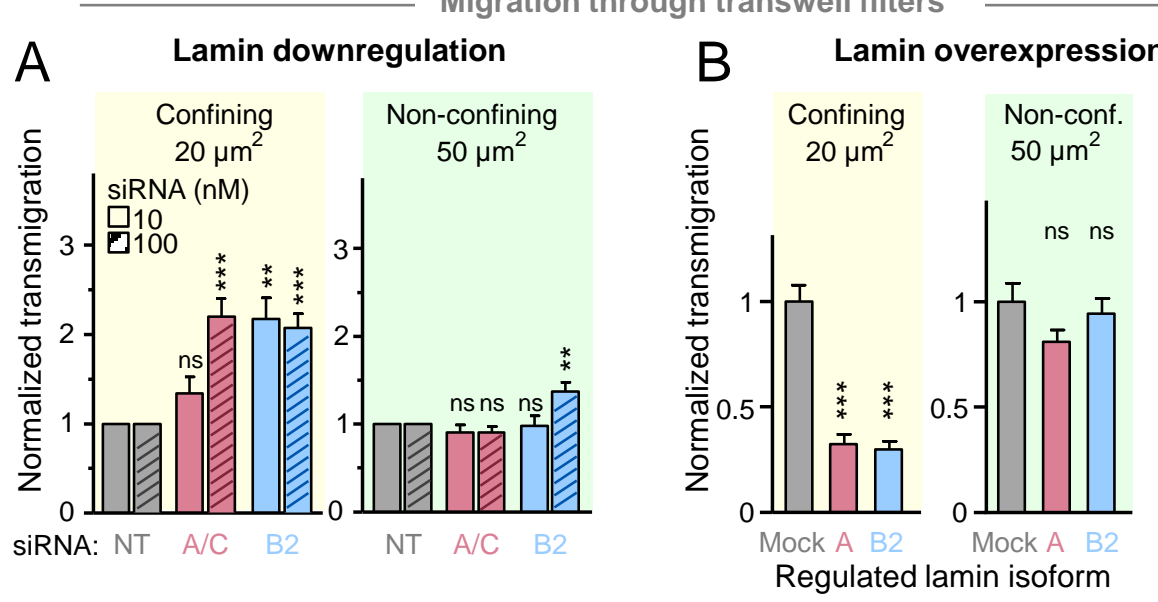

Microchannel
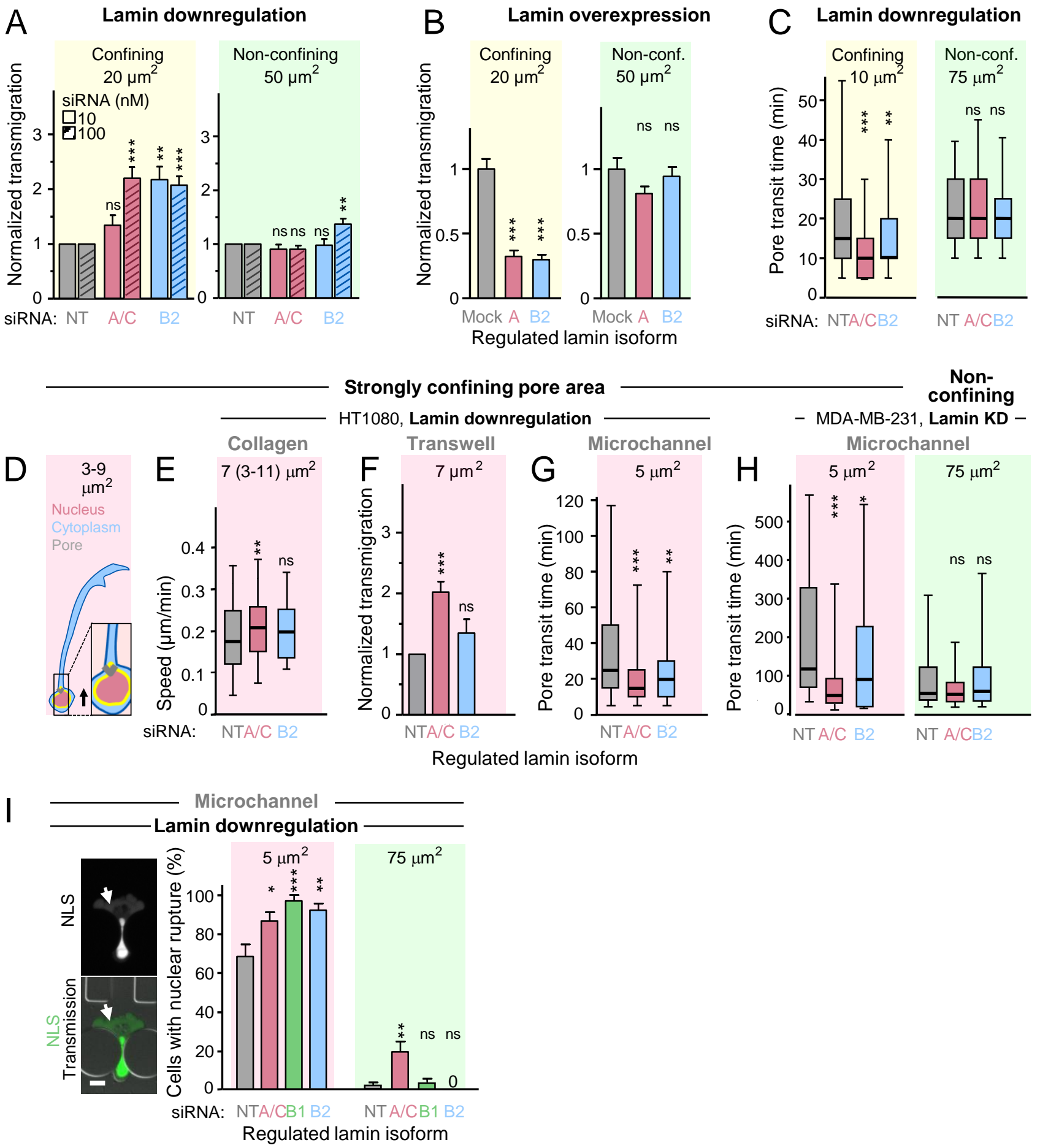

Figure S5. Cell migration and nuclear envelope rupture in synthetic substrates at non-confining, confining and limiting pore conditions. HT1080 (all, except $\mathrm{H}$ ) and MDA-MB-231 (H) cells were modified for lamin expression as indicated and allowed to migrate through transwell membranes $(\mathbf{A}, \mathbf{B}, \mathbf{F})$, microchannel devices $(\mathbf{C}, \mathbf{G}, \mathbf{H}, \mathbf{I})$, or collagen $(\mathbf{E})$. $(\mathbf{A}, \mathbf{B}, \mathbf{F})$ Depiction of transmigration rates of cells that have successfully transmigrated to the lower side of the transwell membrane through pores at indicated cross-sections (see Fig. 4A). Values were normalized towards means of transmigrated control cell numbers at indicated conditions (prior to normalization, after applying 10.000 cells to the upper compartment, approximately 2500,1200 and 600 cells transmigrated through the 8,5 and $3 \mu \mathrm{m}$ transmembrane filters, respectively). $\mathrm{N}=2-7$. $(\mathbf{C}, \mathbf{G}, \mathrm{H})$ Cell migration through through a 3D PDMS microchannel device (see Fig. 4C). Depicted is the time for colored cell nuclei to pass indicated pore cross sections. (C,G) $N=3$; 53-61 HT1080 cells per condition; (H) $n=3 ; 23-50$ MDA-MB-231 cells per condition. (I) Left, images of cells with NLS leakage into the cytoplasm (arrow) indicative of nuclear envelope rupture in the moment of transmigration through a $5 \mu \mathrm{m}^{2}$ constriction. Bar, $10 \mu \mathrm{m}$. Right, incidence of NE rupture after lamin A/C, B1 or B2-specific RNAi, or nontarget (NT) control. N = 3; 36-60 cells per condition. (D) Depiction of cell and nuclear morphology at limiting pore size (red background coloring; Wolf et al., 2013). Nuclei are round or contain occasional thin protrusions with a deformation limit of $\leq 3 \mu \mathrm{m}$ diameter or around $7 \mu \mathrm{m}^{2}$ cross section that cannot be exceeded further (Wolf et al., 2013). Likewise, migrationabrogated cells form long cytoplasmic protrusions. Nearly abrogated cell locomotion rate is depicted by short arrow length (compare with Figure $3 \mathrm{~A}$ ). (E) Mean single cell migration rates in rat tail collagen $(2.5 \mathrm{mg} / \mathrm{ml})$ in the presence of $\mathrm{GM} 6001 ; \mathrm{n}=1-4,8-141 \mathrm{cells}$. (A,B,F,I) Bar diagrams, mean + SEM. $(\mathbf{C}, \mathbf{E}, \mathbf{G}, \mathbf{H})$ Box plot diagrams; horizontal lines, boxes and whiskers show the medians, $25^{\text {th }} / 75^{\text {th }}$, and $5^{\text {th }} / 95^{\text {th }}$ percentile. $* * *, P<0.001 ; * *$, $\mathrm{P}<0.01 ;{ }^{*}, \mathrm{P}<0.05 ; \mathrm{ns}$, non-significant. (A,B,F,I) Two-tailed unpaired Students t-test; $(\mathbf{C}, \mathbf{E}, \mathbf{G}, \mathbf{H})$ non-paired Mann-Whitney test. KD, knockdown. 